S. Huang, W. Zuo, H. Lu, C. Liang, X. Zhang 2019. "Performance Comparison of A Heating Tower Heat Pump and An Air-source Heat Pump: A Comprehensive Modeling and Simulation Study." Energy Conversion and Management, 180, pp. 1039-1054. DOI: 10.1016/j.enconman.2018.11.050.

\title{
Performance comparison of a heating tower heat pump and an air-source heat pump: A comprehensive modeling and simulation study
}

\author{
Shifang Huang ${ }^{\mathrm{a}, \mathrm{b}}$, Wangda Zuo ${ }^{\mathrm{b}}$, Huixia Luc ${ }^{\mathrm{c}}$, Caihua Liang ${ }^{\mathrm{a}}$, Xiaosong Zhang ${ }^{\mathrm{a}, *}$ \\ ${ }^{a}$ School of Energy and Environment, Southeast University, Nanjing, 210096, PR China \\ ${ }^{\mathrm{b}}$ Department of Civil, Environmental and Architectural Engineering, University of Colorado Boulder, Boulder, CO 80309, U.S.A. \\ ${ }^{\mathrm{c}}$ Nanjing TICA Climate Solutions Co., Ltd, Nanjing, 210046, PR China \\ * Corresponding author. \\ E-mail address: rachpe@seu.edu.cn (Xiaosong Zhang).
}

\begin{abstract}
The heating tower heat pump (HTHP) is proposed as an alternative to the conventional air-source heat pump (ASHP). To investigate the performance improvements of the HTHP over the ASHP, a comprehensive comparison between the two systems was carried out based on a simulation study. Physics-based models for the ASHP and HTHP were developed. The performance of the ASHP under frosting conditions was corrected with a newly developed frosting map, and the regeneration penalization was considered for the HTHP. Based on the models and corrections, hourly simulations were carried out in an office building in Nanjing, China. The results show that the average energy efficiency of the HTHP in summer is $23.1 \%$ higher than that of the ASHP due to the water-cooled approach adopted by the HTHP. In winter, the HTHP achieves an increase of 7.4\% in efficiency due to the frost free and energy storage characteristics. While the initial cost of the HTHP is 1.2\% higher than that of the ASHP, the HTHP can still save 9.7\% cost in a 10-year period because of its lower power consumption.
\end{abstract}

Key words: heating tower heat pump; air-source heat pump; modeling; hourly simulation; performance comparison; working mechanism

\section{Introduction}

In warm and mixed climate regions defined by ASHRAE ${ }^{[1]}$, such as eastern and central China, south-central and southeastern America, and western and southern of Europe, both heating and cooling supply are in great demand due to its special climate condition. Currently, the cooling and heating demand of buildings in these regions is 
mainly satisfied by air-source heat pumps (ASHPs). Because they can implement both cooling and heating and are easy to install and maintain. However, the efficiency of the ASHP is lower than water-cooled chillers in summer ${ }^{[2]}$. Even worse, frosting in winter can significantly reduce both the energy efficiency and the heating capacity of $\operatorname{ASHP}^{[3,4]}$. To address the frosting issue, several approaches have been proposed, such as reverse cycle defrosting ${ }^{[5]}$, new designed heat exchanger ${ }^{[6]}$, and liquid desiccant preprocessing ${ }^{[7,8]}$. However, there are some side effects associated with these approaches as they may reduce the heating capacity or increase energy consumption and investment.

To address the issues mentioned above, heating tower heat pumps (HTHPs), as novel integrated heating and cooling units, have been proposed as an alternative to the conventional ASHPs. As for heating towers, the thermal characteristics and the calculation method of heating towers have attracted the most attention because they are the foundations of tower design. Fujita and Kametani ${ }^{[9]}$ carried out experiments in counter/cross flow towers. The towers were packed with tube using water and ethylene glycol aqueous as working fluid. Based on this, they expressed the heating capacity of the tower by a function of overall enthalpy transfer coefficient and enthalpy difference between air and solution. Tan et al. ${ }^{[10]}$ made a revision on the Merkel's equation of standard cooling towers to calculate the thermal characteristics of a heating tower. Zhang et al. ${ }^{[11]}$ developed a coupled heat and mass transfer model for the counter-flow heating tower and validated the model with the experimental data reported by Tan et $\mathrm{al}^{[10]}$. Wen et al. ${ }^{[12]}$ calculated the heat transfer coefficient of a cross-flow heating tower by assuming Lewis number equal to one and using the coupled heat and mass transfer model. To advance Wen's study, Lu et al. ${ }^{[13]}$ conducted a numerical study of a counter-flow heating tower considering the changeable Lewis number. However, the heat transfer coefficient was taken from a study on a super large cooling tower for a power plant, which had a completely different process from the heating tower used for buildings. In order to calculate more valid heat and mass transfer coefficients, Huang et al. ${ }^{[13]}$ experimentally investigated the heat and mass transfer characteristics in a crossflow heating tower. More specifically, both heat and mass transfer coefficients were obtained using a finite difference method without the pre-assumption of Lewis number. Song et al. ${ }^{[14]}$ conducted a similar study where a closed-type heat-source tower was used and found that the mass transfer coefficient had a magnitude equal to that of the liquid desiccant dehumidifier.

Among the previous research regarding the HTHP system, the coefficient of performance (COP) of the system is of the most importance. Table 1 summaries the tower type, circulating fluid, compressor type, heating capacity, weather data, and the COP in the experiments mentioned in the literatures. The hot water supplied by those HTHP systems was kept around $45^{\circ} \mathrm{C}$, with an exception of Cheng's work $\left(35^{\circ} \mathrm{C}\right)^{[15]}$. The main conclusions drawn in those studies are summarized as follows: 1) the HTHP has a good performance in cold and humid weather; 2) the HTHP has no frosting problem in cold and humid weather, which is inevitable for the ASHP.

Table 1. The performance of the HTHP in literatures

\begin{tabular}{|l|l|l|l|l|l|l|}
\hline Literature & Tower type & Circulating fluid & Compressor & Heating capacity & Outdoor weather & COP \\
\hline
\end{tabular}




\begin{tabular}{|l|l|l|l|l|l|l|}
\hline Liang et al. ${ }^{[16]}$ & Open-type & Ethylene glycol & Rotor & {$[4.57,5.37] \mathrm{kW}$} & $\mathrm{T}_{\mathrm{a}}=-2^{\circ} \mathrm{C}$ & {$[2.72,3.02]$} \\
\hline Wu et al. ${ }^{[17]}$ & Open-type & Calcium chloride & Screw & $125 \mathrm{~kW}$ & $\mathrm{~T}_{\mathrm{a}}=4.6^{\circ} \mathrm{C}, \varphi_{\mathrm{a}}=90 \%$ & {$[2.70,2.86]$} \\
\hline Zhang et al. ${ }^{[18]}$ & Open-type & Ethylene glycol & Rotor & $6.57 \mathrm{~kW}$ & $\mathrm{~T}_{\mathrm{a}}=6.5^{\circ} \mathrm{C}, \varphi_{\mathrm{a}}=76 \%$ & 3.02 \\
\hline Li et al. ${ }^{[19]}$ & Closed-type & Urea & Screw & $125 \mathrm{~kW}$ & $\begin{array}{l}\mathrm{T}_{\mathrm{a}}=[-1, \quad 5] \quad{ }^{\circ} \mathrm{C}, \\
\varphi_{\mathrm{a}}=[71 \%, 95 \%]\end{array}$ & {$[2.58,3.90]$} \\
\hline Cheng et al. ${ }^{[15]}$ & Closed-type & Not mentioned & Scroll & $809 \mathrm{~kW}$ & $\mathrm{~T}_{\mathrm{a}}=4.3^{\circ} \mathrm{C}, \varphi_{\mathrm{a}}=93.9 \%$ & 3.0 \\
\hline
\end{tabular}

The experiments listed in Table 1 were conducted under special winter conditions. However, the annual performance of the HTHP is preferred when designing and evaluating a cooling and heating system for a building. While the HTHP systems have the same working principles as chillers with cooling towers in summer, they are different in some technique details, such as the size and flow rate of the towers, and the material of the heat exchangers. Therefore, the manufacturer data or existing investigations of chillers with cooling towers cannot be directly used to assess the performance of the HTHP in summer. Furthermore, a HTHP needs additional energy input for a regeneration process to maintain the concentration of solution in winter ${ }^{[20,21]}$. However, current studies of HTHP system did not consider the regeneration penalization in winter, which would lead to higher COP. Since the summer performance and winter regeneration penalization are ignored in existing studies, the comparisons of the performance of the HTHP versus the ASHP are not comprehensive. To enable an informed decision on the selection of HTHP and ASHP for industrial applications, it is necessary to perform a comprehensive performance comparison of these two systems.

This study first introduces a typical AHSP and HTHP. Then, physics-based models for the HTHP and ASHP are developed by coupling the solution cycle, refrigerant cycle, and chilled/hot water cycle. Besides, a new frosting map is developed and adopted to analyze the ASHP's performance under frosting conditions. Based on the models, the impacts of the HTHP with and without considering the summer performance and winter regeneration are compared. After that, a comprehensive comparison between the ASHP and HTHP with summer performance and winter regeneration are carried out. This includes typical day analysis, annual performance analysis, and economic analysis.

\section{System description of ASHP and HTHP}

Fig. 1 (a) and (b) show the schematics of a typical ASHP and HTHP, respectively. To make comparisons with the HTHP, we built a comparable ASHP model, which consists of a shell-tube evaporator, finned-tube condensers (the evaporators and condensers are named under summer condition), scroll compressors, thermal expansion valves, and four-way reversing valves. The ASHP switches cooling and heating modes with four-way reversing valves, as shown in Fig. 1 (a). The HTHP model was built based on a real system, consisting of a cross-flow heating tower, a shell-tube evaporator and condenser, scroll compressors, thermal expansion valves, pumps and valves. The HTHP 
1 are opened and valves 5 8 are closed. The HTHP runs similar to water chillers with cooling towers. Water is adopted 2 as the working fluid in the tower cycle to reject heat from the heat pump to the atmosphere. The mass balance in 3 this process is achieved by adding make-up water. In the winter conditions, the state of all the valves is opposite to 4 that in summer. Water is replaced by solution (e.g. glycol aqueous) with low freezing point to protect the system 5 from freezing. The solution from the evaporator is pumped into the heating tower for heat absorption. In most winter conditions, water vapor will be absorbed into the solution. Thereby, a solution regeneration system based on vacuum boiling and condensation is equipped to protect the solution from dilution ${ }^{[21]}$.

In order to carry out a fair comparison, the studied ASHP and HTHP adopt the same common components (the shell-tube exchangers, compressors and expansion valves) as listed in

Table 2. The size of the finned-tube heat exchanger is selected according to the logarithmic mean temperature difference (LMTD) between the air and refrigerant. In the design condition, the LMTD is $9.9^{\circ} \mathrm{C}$ (the LMTD is around $10^{\circ} \mathrm{C}$ for industrial practice). The size of the heating tower is selected based on the water/solution inlet and outlet temperatures of the existing products. In the design summer condition (dry-bulb/wet-bulb temperature is $32.0^{\circ} \mathrm{C}$ $/ 28.0^{\circ} \mathrm{C}$ ), the water inlet and outlet temperatures are kept at $35.9^{\circ} \mathrm{C}$ and $30.8^{\circ} \mathrm{C}$, respectively. In the design winter condition (dry-bulb/wet-bulb temperature is $7.0^{\circ} \mathrm{C} / 4.3^{\circ} \mathrm{C}$ ), the solution inlet and outlet temperatures are $1.0^{\circ} \mathrm{C}$ and $-1.1^{\circ} \mathrm{C}$, respectively.

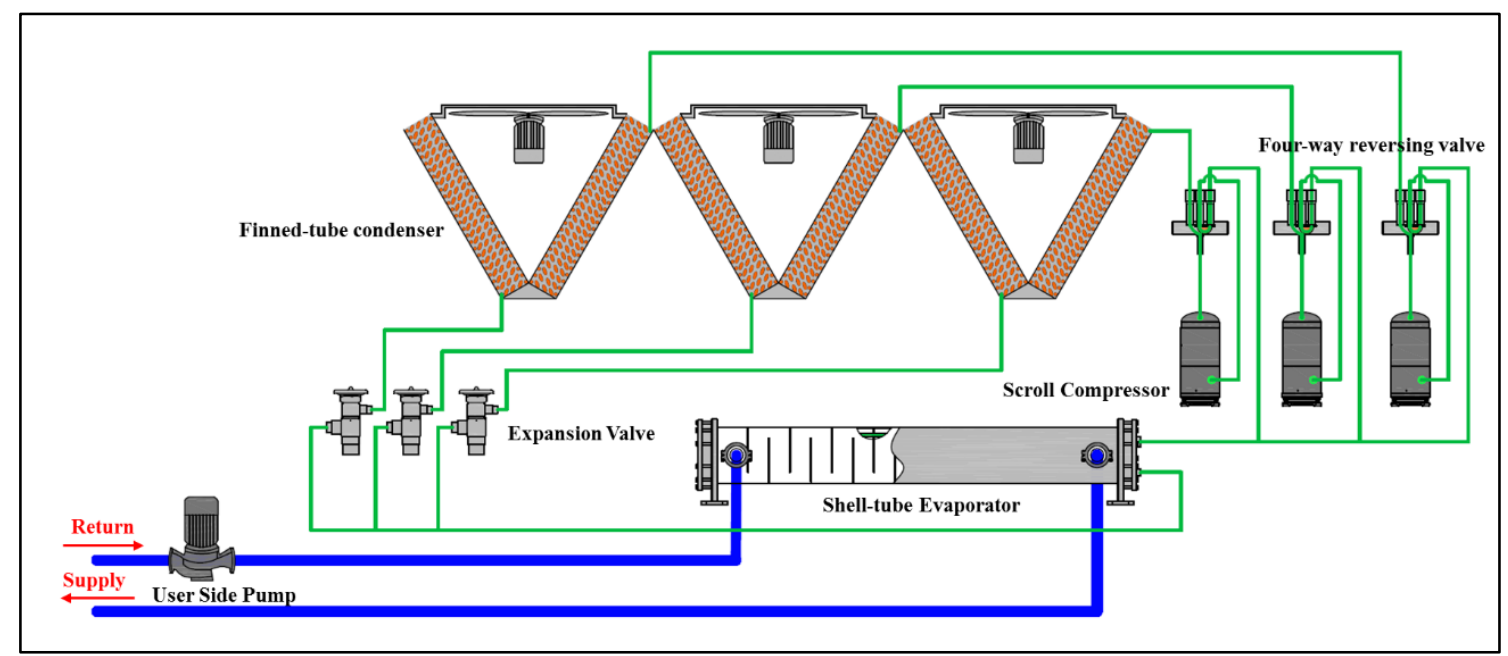

(a) ASHP 


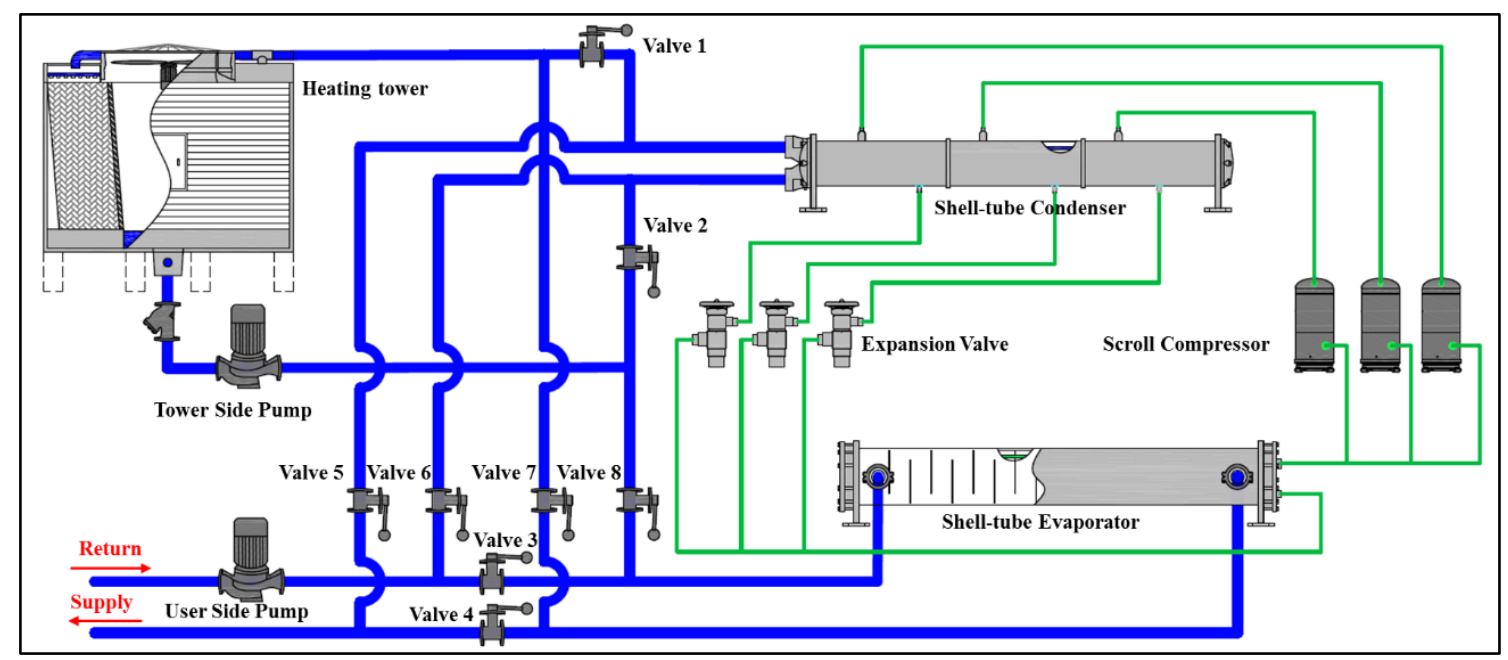

(b) HTHP

Fig. 1. Schematics of an air-source heat pump and a heating tower heat pump

Table 2. Parameters of system components of ASHP and HTHP

\begin{tabular}{|c|c|}
\hline Components & Parameters \\
\hline Heating tower & $\begin{array}{l}\text { PVC structured packings: length } \times \text { width } \times \text { height }=2 \times 0.76 \times 2 \mathrm{~m} \text { (each side) } \\
\text { Specific surface area: } 172 \mathrm{~m}^{2} \mathrm{~m}^{-3} \\
\text { Tower fan: flow rete } 43000 \mathrm{~m}^{3} \mathrm{~h}^{-1} \text {, power } 4 \mathrm{~kW} \text { (rated condition) } \\
\text { Tower side pump: flow rate } 35 \mathrm{~m}^{3} \mathrm{~h}^{-1} \text {, head } 22 \mathrm{~m} \text {, power } 3.8 \mathrm{~kW} \text { (rated condition) }\end{array}$ \\
\hline Scroll compressor & $\begin{array}{l}\text { Type: Copeland VR190KS-TFP } \\
\text { Displacement: } 258 \mathrm{~g} \mathrm{~s}^{-1}\end{array}$ \\
\hline Shell-tube evaporator & $\begin{array}{l}\text { Heat exchange area: } 10.5 \mathrm{~m}^{2} \\
\text { Tube side: R22, tube size } \Phi 12.7 \times 1.0 \text {, tube length } 2000 \mathrm{~mm} \text {, tube number } 134 \text {, single flow, } 15 \% \\
\text { copper-nickel alloy, internal thread } \\
\text { Shell side: Water/solution, shell size } \Phi 273 \times 8 \text {, double flow, baffle thickness } 50 \mathrm{~mm} \text {, baffle number } 17\end{array}$ \\
\hline Shell-tube condenser & $\begin{array}{l}\text { Heat exchange area: } 7.2 \mathrm{~m}^{2} \\
\text { Tube side: Water/solution, tube size } \Phi 15.9 \times 1.0 \text {, tube length } 2000 \mathrm{~mm} \text {, tube number } 72 \text {, double flow, } \\
\text { red copper, external reticulation } \\
\text { Shell side: } \mathrm{R} 22, \Phi 273 \times 8,2000 \mathrm{~mm} \times 1 \text {, single flow, division plate } 28 \mathrm{~mm} \times 2\end{array}$ \\
\hline Finned-tube condenser & $\begin{array}{l}\text { Heat exchange area: } 468.4 \mathrm{~m}^{2} \\
\text { Tube side: } \mathrm{R} 22, \Phi 10 \times 0.5 \text {, tube length } 3000 \mathrm{~mm} \text {, tube number } 80 \times 4 \text {, regular triangular arrangement, } \\
\text { tube distance } 25 \mathrm{~mm} \text {, fin height } 2 \mathrm{~mm} \text {, fin distance } 0.15 \mathrm{~mm} \text {, red copper } \\
\text { Air side: Air, flow rate } 54000 \mathrm{~m}^{3} \mathrm{~h}^{-1} \text {, power } 4 \mathrm{~kW} \text { (rated condition) }\end{array}$ \\
\hline Thermal expansion valve & Type: Danfoss TGEX15TR \\
\hline
\end{tabular}

\section{Mathematical modeling of ASHP and HTHP}

The performance of the ASHP under different conditions are calculated by a physics-based model with a

5 frosting map $^{[3]}$. The performance of the HTHP is computed by a physics-based model coupling the solution cycle, 
1 refrigerant cycle, and chilled/hot water cycle. As indicated in Section 2, the two systems have several components.

2 Each component is calculated separately and then linked through the input and output parameters. Conservation equations of energy, mass, and convective heat and mass transfer are applied. Some general assumptions to develop

4 the mathematical models are as follows:

5 (1) All system components are operating under steady-state conditions in the selected time interval.

6 (2) Heat loss of the components to the surroundings is assumed to be negligible.

7 (3) The expansion valve undergoes an isenthalpic process.

8 (4) The heat and mass transfer coefficients are uniform throughout the packing of the heating tower.

9 (5) Packing is well wet, and the areas of heat and mass transfer are both equal to the surface area of the packing.

(6) The contribution of conduction or diffusion to the total heat and mass transfer can be neglected in the flow 11 directions.

\subsection{Compressor}

The values of the mass flow rate of refrigerant, $m_{R}$, and power input of compressor, $W_{\text {comp }}$, can be expressed by a function of the evaporating temperature, $t_{e}$, and condensing temperature, $t_{c}$, as shown in Eqs.(1) and (2) ${ }^{[22]}$ :

$$
\begin{aligned}
& m_{R}=\pi_{1}+\pi_{2} t_{e}+\pi_{3} t_{c}+\pi_{4} t_{e}^{2}+\pi_{5} t_{e} t_{c}+\pi_{6} t_{c}^{2}+\pi_{7} t_{e}^{3}+\pi_{8} t_{e}^{2} t_{c}+\pi_{9} t_{e} t_{c}^{2}+\pi_{10} t_{c}^{3}, \\
& W_{\text {comp }}=\beta_{1}+\beta_{2} t_{e}+\beta_{3} t_{c}+\beta_{4} t_{e}^{2}+\beta_{5} t_{e} t_{c}+\beta_{6} t_{c}^{2}+\beta_{7} t_{e}^{3}+\beta_{8} t_{e}^{2} t_{c}+\beta_{9} t_{e} t_{c}^{2}+\beta_{10} t_{c}^{3},
\end{aligned}
$$

where the regression coefficients, $\pi_{i}$ and $\beta_{i}$, are fitted from the data provided by the product selection software of Copeland with Levenberg-Marquardt method. The results of the regression are given in Table 3. When the actual superheat in the suction of the compressor is different from the rated superheat value, both the mass flow rate and the power input can be adjusted by using the change in suction specific volume $v_{\text {rated }} / v_{\text {real }}$.

Table 3. Regression coefficients of Eqs. (1) and (2)

\begin{tabular}{|l|l|l|l|}
\hline \multicolumn{2}{|l|}{ Regression coefficients of Eq. (1) } & \multicolumn{2}{l|}{ Regression coefficients of Eq. (2) } \\
\hline$\pi_{l}$ & $2.696 \times 10^{2}$ & $\beta_{I}$ & 4.505 \\
\hline$\pi_{2}$ & 8.461 & $\beta_{2}$ & $3.547 \times 10^{-2}$ \\
\hline$\pi_{3}$ & -1.881 & $\beta_{3}$ & $1.107 \times 10^{-1}$ \\
\hline$\pi_{4}$ & $1.261 \times 10^{-1}$ & $\beta_{4}$ & $5.832 \times 10^{-6}$ \\
\hline$\pi_{5}$ & $-3.693 \times 10^{-2}$ & $\beta_{5}$ & $8.214 \times 10^{-5}$ \\
\hline$\pi_{6}$ & $5.741 \times 10^{-2}$ & $\beta_{6}$ & $-2.706 \times 10^{-4}$ \\
\hline$\pi_{7}$ & $1.154 \times 10^{-3}$ & $\beta_{7}$ & $-8.487 \times 10^{-7}$ \\
\hline$\pi_{8}$ & $-1.006 \times 10^{-3}$ & $\beta_{8}$ & $1.705 \times 10^{-6}$ \\
\hline$\pi_{9}$ & $9.011 \times 10^{-4}$ & $\beta_{9}$ & $-9.203 \times 10^{-6}$ \\
\hline$\pi_{l 0}$ & $-7.020 \times 10^{-4}$ & $\beta_{10}$ & $2.340 \times 10^{-5}$ \\
\hline
\end{tabular}

\subsection{Heat exchanger}

\section{$21 \quad$ 3.2.1 Equations of conservation and convective heat and mass transfer}


When the evaporator/condenser reaches a steady-state condition, the energy balance between the refrigerant and water/air/solution is achieved. Therefore, the cooling capacity of the evaporator, $Q_{e}$, can be expressed by both the refrigerant heat transfer capacity and water/air/solution heat transfer capacity, as show in Eqs. (3) and (4).

$$
\begin{aligned}
& Q_{e}=m_{R}\left(h_{1}-h_{4}\right), \\
& Q_{e}=m_{w} C p_{w}\left(t_{w, i}-t_{w, o}\right) \text { or } Q_{e}=m_{a} C p_{a}\left(t_{a, i}-t_{a, o}\right) \text { or } Q_{e}=m_{s} C p_{s}\left(t_{s, i}-t_{s, o}\right),
\end{aligned}
$$

where $h_{1}$ and $h_{4}$ are the enthalpy of the refrigerant in the inlet and outlet of the evaporator. The $m, C p$, and $t$ are the mass flow rate, specific heat at constant pressure, and temperature of the fluid through the evaporator, respectively. The subscripts $w, a$, and $s$ represent water, air, and solution, respectively. The subscripts $i$ and $o$ represent inlet and outlet of the heating tower, respectively. Also, the cooling capacity of the evaporator can be calculated according to the convective heat transfer, as show in Eq. (5).

$$
Q_{e}=K_{e} A_{e} \Delta t_{e},
$$

where $K_{e}$ and $A_{e}$ are the heat transfer coefficient and area of the evaporator. The $\Delta t_{e}$ is the logarithmic mean temperature difference between the refrigerant and water/air/solution. Similarity, the heating capacity of the condenser, $Q_{c}$, can be expressed by the following equations:

$$
\begin{aligned}
& Q_{c}=m_{R}\left(h_{2}-h_{3}\right), \\
& Q_{c}=m_{w} C p_{w}\left(t_{w, o}-t_{w, i}\right) \text { or } Q_{c}=m_{a} C p_{a}\left(t_{a, o}-t_{a, i}\right), \\
& Q_{c}=K_{c} A_{c} \Delta t_{c},
\end{aligned}
$$

where the subscript $c$ indicates the property for condenser. The $h_{2}$ and $h_{3}$ are the enthalpy of the refrigerant in the inlet and outlet of the condenser.

\subsubsection{Equations of heat transfer coefficients}

\section{Coefficient for evaporation of R22 inside the tube ${ }^{[7]}$}

When the R22 evaporates inside the tube, the process contains both single-phase and two-phase heat transfer. The single-phase heat transfer coefficient, $K_{R, l}$, of the refrigerant inside the tube is calculated by Dittus-Boeler formula:

$$
K_{R, l}=0.023 R e_{R, l}^{0.8} \operatorname{Pr}_{R, l}^{0.4} \frac{\lambda_{R, l}}{d_{i}},
$$

where $R e_{R, l}$ is the Reynolds number, and $P r_{R, l}$ is the Prandtl number of the process. $\lambda_{R, l}$ represents the thermal conductivity coefficient of the liquid phase refrigerant. The $d_{i}$ is the inner diameter of the tube. The two-phase heat transfer coefficient, $K_{R, T P}$, can then be described as:

$$
\begin{aligned}
& K_{R, T P}=K_{R, l}\left[c_{1}\left(c_{0}\right)^{c_{2}}\left(\frac{25 G_{R}^{2}}{9.8 \rho_{R, l}^{2} d_{i}}\right)^{c_{5}}+2.2 c_{3}\left(\frac{q_{R, i}}{G_{R} r_{R}}\right)^{c_{4}}\right], \\
& c_{0}=\left(\frac{1-x}{x}\right)^{0.8}\left(\frac{\rho_{R, g}}{\rho_{R, l}}\right)^{0.5},
\end{aligned}
$$


9

where $G_{R}, \rho_{R, l}, \rho_{R, g}, r_{R}, q_{R, i}$, and $x$ are the mass flow flux, liquid phase density, gas phase density, vaporization latent heat of the refrigerant, inner heat flux, and dryness of the refrigerant, respectively. The $c_{0}$ is the characteristic number of convection heat transfer, and $c_{1}-c_{5}$ are constants depending on $c_{0}$.

Coefficient for condensation of R22 inside the tube ${ }^{[23]}$

$$
K_{R}=0.683\left(\frac{9.8 \lambda_{R, l}^{3} \rho_{R, l}^{2} r_{R}}{u_{R, l}}\right)^{0.25} d_{i}^{-0.25}\left(t_{c}-t_{w a l l}\right)^{-0.25},
$$

where $u_{R, l}$ is liquid phase dynamic viscosity of the refrigerant. The $t_{w a l l}$ is the temperature of the tube wall.

Coefficient for condensation of R22 outside the tube ${ }^{[24]}$

$$
K_{R}=0.725\left(\frac{9.8 \lambda_{R, l}^{3} \rho_{R, l}^{2} r_{R}}{u_{R, l}}\right)^{0.25} d_{o}^{-0.25}\left(t_{c}-t_{\text {wall }}\right)^{-0.25} \Psi_{1} \varepsilon_{1}
$$

where $d_{o}$ is the external diameter of the tube. The $\Psi_{1}$ and $\varepsilon_{1}$ are correction factors depending on the size and arrangement of tubes.

\section{$\underline{\text { Coefficients for water and solution across the tubes }}{ }^{[24]}$}

The coefficient for water across the tubes $\left(K_{w}\right)$ can be expressed as follow:

$$
K_{w}=0.22 R e_{w}^{0.6} \operatorname{Pr}_{w}^{1 / 3} \frac{\lambda_{w}}{d_{0}}
$$

where $R e_{w}$ is the Reynolds number, and $P r_{w}$ is the Prandtl number of the water. $\lambda_{w}$ represents the thermal conductivity coefficient of water. Similarity, the coefficient for solution across the tubes, $K_{S}$, can be expressed by the following equation:

$$
K_{s}=0.22 \operatorname{Re}_{s}^{0.6} \operatorname{Pr}_{s}^{1 / 3} \frac{\lambda_{s}}{d_{0}},
$$

where the subscript $\mathrm{s}$ indicates the property for solution.

\section{Coefficients for water and solution inside the tube ${ }^{[24]}$}

The coefficient for water inside the tube, $K_{w}$, can be expressed as Eq. (16), and that of solution, $K_{S}$, can be calculated as Eq. (17).

$$
\begin{aligned}
& K_{w}=0.023 R e_{w}^{0.8} \operatorname{Pr}_{w}^{0.4} \frac{\lambda_{w}}{d_{i}}, \\
& K_{s}=0.023 R e_{s}^{0.8} \operatorname{Pr}_{s}^{0.4} \frac{\lambda_{s}}{d_{i}} .
\end{aligned}
$$

\section{$\underline{\text { Coefficient for air across the finned-tubes }}^{[23]}$}

The coefficient for air across the finned-tubes, $K_{a}$, is show as follow: 


$$
K_{a}=\Psi_{2} \varepsilon_{2} \frac{\lambda_{a}}{d_{e}} R_{a}^{n}\left(\frac{b}{d_{e}}\right)^{m}
$$

where $R e_{a}$ is the Reynolds number of air. The $\lambda_{a}$ represents the thermal conductivity coefficient of air. $d_{e}$ is the equivalent diameter of the narrowest section, and $b$ is the width of fin. The $\Psi_{2}, \varepsilon_{2}, n$, and $m$ are constants depending on the value of $\frac{b}{d_{e}}$ and $R e_{a}$.

\section{$\underline{\text { Overall heat transfer coefficient }}^{[23]}$}

Based on the coefficients of refrigerant and water/air/solution, the overall heat transfer coefficient for the evaporator or condenser, $K$, can be expressed as a function of the heat transfer coefficient inside the tube, $K_{i}$, and outside the tube, $K_{o}$ :

$$
K=\frac{1}{\left(\frac{1}{K_{i}}+R_{i}\right) \frac{A_{O}}{A_{i}}+\frac{\delta A_{O}}{\lambda_{\text {wall }} A_{m}}+R_{o}+\frac{1}{K_{o}}},
$$

where $A$ is the heat transfer area, and $R$ is the heat transfer resistance. The $\delta$ is the thickness of the wall, and $\lambda_{\text {wall }}$ is the thermal conductivity coefficient of the wall. The subscripts $i$ and $o$ represent the property inside and outside the tube, respectively.

\subsubsection{Equations for heat exchangers in ASHP and HTHP}

The above equations are then used to describe the heat transfer process of the heat exchangers under different working conditions with different working fluid, as summarized in Table 4.

\begin{tabular}{|c|c|c|c|c|}
\hline System & Condition & Heat exchanger & Inside tube / outside tube & Equation \\
\hline \multirow{4}{*}{ ASHP } & \multirow{2}{*}{ Summer } & Shell-tube evaporator & R22 / Water & (3) (4) (5) (9) (10) (11) (14) (19) \\
\hline & & Finned-tube condenser & R22 / Air & $(6)(7)(8)(12)(18)(19)$ \\
\hline & \multirow{2}{*}{ Winter } & Finned-tube evaporator & R22 / Air & $(3)(4)(5)(9)(10)(11)(18)(19)$ \\
\hline & & Shell-tube condenser & R22 / Water & $(6)(7)(8)(12)(14)(19)$ \\
\hline \multirow{4}{*}{ HTHP } & \multirow{2}{*}{ Summer } & Shell-tube evaporator & R22 / Water & $(3)(4)(5)(9)(10)(11)(14)(19)$ \\
\hline & & Shell-tube condenser & Water / R22 & $(6)(7)(8)(13)(16)(19)$ \\
\hline & \multirow{2}{*}{ Winter } & Shell-tube evaporator & R22 / Solution & $(3)(4)(5)(9)(10)(11)(15)(19)$ \\
\hline & & Shell-tube condenser & Water / R22 & $(6)(7)(8)(13)(16)(19)$ \\
\hline
\end{tabular}

Table 4. Equations for heat exchangers

\subsection{Frosting-map-based correction for finned-tube evaporator}

When the finned-tube heat exchanger works as a condenser in summer, only heat transfer occurs on the surface of finned-tube. However, when the finned-tube heat exchanger is used as an evaporator in winter, three working conditions can take place: dry condition, wet condition, and frosting condition. In the wet condition, both heat and mass transfer should be considered. In the frosting condition, the performance of the finned-tube evaporator will be 
significantly reduced due to the increase of air friction and thermal resistance of the frost layer. Thus, a correction on the performance of finned-tube evaporator is needed to reflect this performance drop. The correctional heat transfer capacity of the evaporator, $Q_{e}^{*}$, can be expressed as the following equation:

$$
Q_{e}^{*}=\eta_{e} Q_{e}
$$

where $\eta_{e}$ is the correction coefficient based on the three working conditions.

A frosting-map-based approach can be used to determine the working conditions and the correction coefficients of the finned-tube evaporator ${ }^{[3]}$. However, in the existing work, the coil temperature of the finned-tube evaporator was calculated according to the data from the field test, which can be different for different ASHPs. In addition, the existing work did not consider the deposition process where water vapor transfers to ice directly. To enable a largescale application, this study then proposed a new frosting map through a parametric analysis. The new frosting map considers the deposition process and calculates the coil temperature of the finned-tube evaporator by the models developed in this study.

The frosting map is defined using the pressure of water in the triple point, $P_{w}$, the temperature of the air freezing point, $t_{f}$, the temperature of the air dew point, $t_{d p}$, and the coil temperature of the finned-tube evaporator, $t_{w a l l}$. Then the map is divided into four zones according to the physical phenomena of condensing and frosting as shown in Fig. 2.

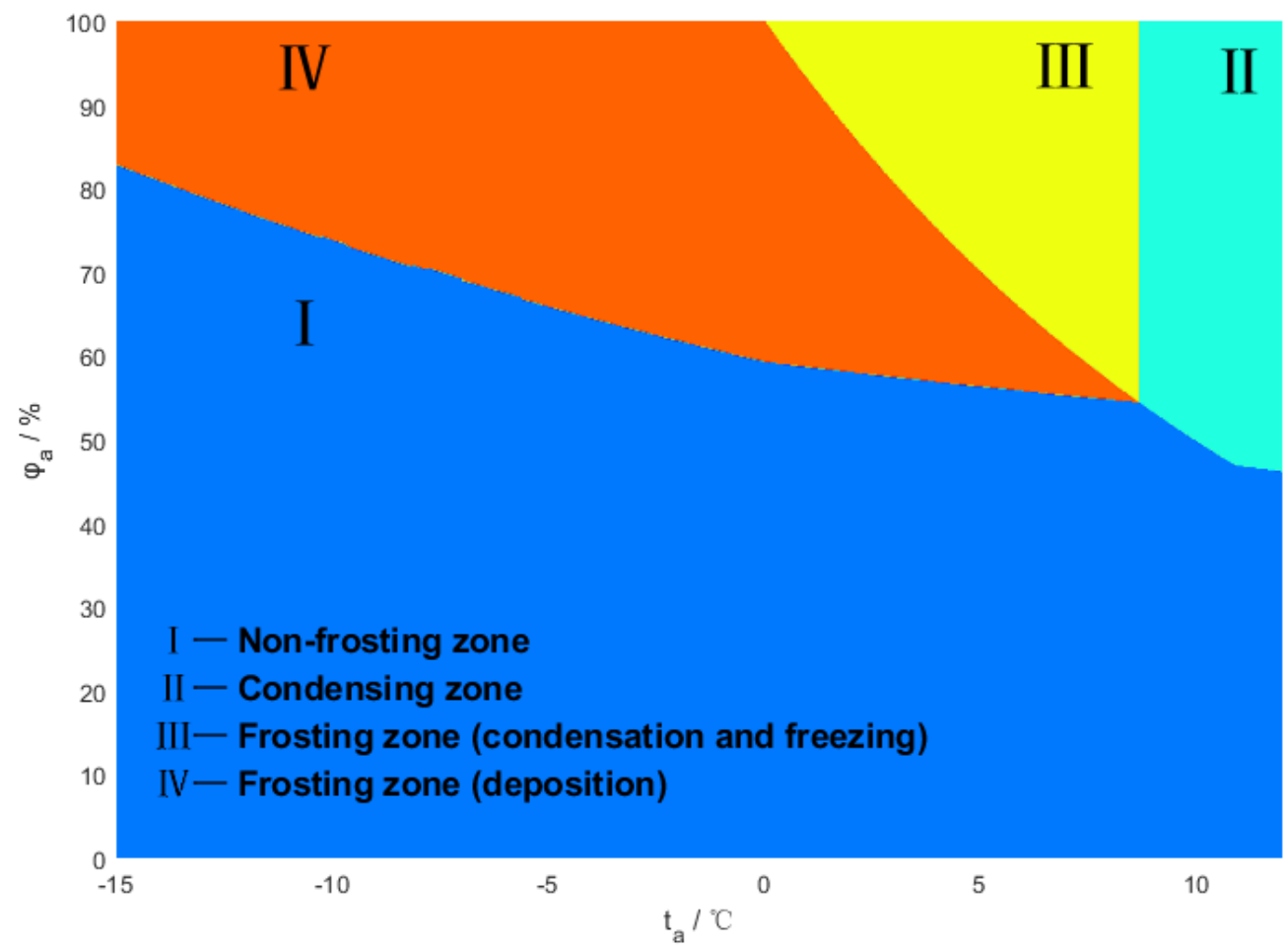

Fig. 2. Frosting map

Zone $I$ is a non-frosting zone. It is defined for the area where $P_{w}>611.73 \mathrm{~Pa}$ and $t_{w a l l}>t_{d p}$. In this zone, neither condensation nor frost occurs on the surface of finned-tube heat exchanger. Thus, the correction coefficient 
is taken as 1 . Zone II is a condensing zone. It covers the area where $P_{w}>611.73 \mathrm{~Pa}$ and $t_{f}<t_{w a l l}<t_{d p}$. The correction coefficient for this zone can be expressed by:

$$
\eta_{e}=\frac{C p_{a}\left(t_{a}-t_{\text {wall }}\right) L e+r_{w}\left(\omega_{a}-\omega_{\text {wall }}\right)}{C p_{a}\left(t_{a}-t_{\text {wall }}\right) L e},
$$

where $L e$ is the Lewis number, $r_{w}$ is the vaporization latent heat of water, $\omega_{a}$ is the air humidity ratio, and $\omega_{\text {wall }}$ is the equivalent humidity ratio of water condensing on the surface of the evaporator.

There are two frosting zones (Zone III and $I V$ ). Zone III is a frosting zone where both condensing and freezing occur when $P_{w}>611.73 \mathrm{~Pa}$ and $t_{w a l l}<t_{f}$. In this zone, the water vapor in the air first condenses on the surface of finned-tube evaporator and then freezes. Zone $I V$ is the other frosting zone where deposition occur when $P_{w}<$ $611.73 \mathrm{~Pa}$ and $t_{\text {wall }}<t_{f}$. In this zone, the water vapor in the air directly transfers to the ice phase bypassing the water phase. The correction for the two frosting zones can be described using a polynomial equation developed from a previous study ${ }^{[25]}$ :

$$
\eta_{e}=-0.043678\left(t_{f}-t_{\text {wall }}\right)+1.0688 \text {. }
$$

Eqs. (22) can be used to calculate the correction coefficients in both Zone III and $I V$. But the calculations of $t_{f}$ in Zone III and $I V$ are different.

To determine the $t_{d p}$ and $t_{f}$ for different zones, one can use the equations for liquid-vapor line, solid-liquid 14 line, and solid-vapor line ${ }^{[26]}$ :

$$
\begin{aligned}
& \ln \left(P_{w}\right)=\sum_{i=1}^{7} \xi_{i} T_{d p}^{i-3}+\xi_{8} \ln \left(T_{d p}\right), \\
& P_{w}=-3.952 \times 10^{7}\left[\left(\frac{T_{f}}{273.16}\right)^{9}-1\right], \\
& \ln \left(P_{w}\right)=\sum_{i=1}^{3} \tau_{i} T_{d p}^{i-2}+\tau_{4} \ln \left(T_{d p}\right),
\end{aligned}
$$

where $T_{d p}$ and $T_{f}$ are the temperature of the dew point and freezing point in Kelvin, respectively. The $\xi_{i}$ and $\tau_{i}$ are the coefficients for the equations, as presented in Table 5.

Table 5. Coefficients of Eqs. (23) and (25) ${ }^{[26]}$

\begin{tabular}{|l|l|l|l|}
\hline \multicolumn{2}{|l|}{ Coefficients of Eq. (23) } & \multicolumn{2}{l|}{ Coefficients of Eq. (25) } \\
\hline$\xi_{1}$ & $-2.8365744 \times 10^{3}$ & $\tau_{1}$ & $-5.723265 \times 10^{3}$ \\
\hline$\xi_{2}$ & $-6.028076559 \times 10^{3}$ & $\tau_{2}$ & $9.550426 \times 10^{1}$ \\
\hline$\xi_{3}$ & $1.954263612 \times 10^{1}$ & $\tau_{3}$ & $-7.28332 \times 10^{-3}$ \\
\hline$\xi_{4}$ & $-2.737830188 \times 10^{-2}$ & $\tau_{4}$ & $3.53068 \times 10^{1}$ \\
\hline$\xi_{5}$ & $1.6261698 \times 10^{-5}$ & & $/$ \\
\hline$\xi_{6}$ & $7.0229056 \times 10^{-10}$ & & $/$ \\
\hline$\xi_{7}$ & $-1.868009 \times 10^{-13}$ & & $/$ \\
\hline$\xi_{8}$ & $2.7150305 \times 10^{1}$ & & $/$ \\
\hline
\end{tabular}


The expansion process in the expansion valve is taken as an isenthalpic process as shown in Eq. (26). $h_{3}=h_{4}$.

3 The mass flow rate of the refrigerant can be calculated by Eq. $(27)^{[27]}$.

$m_{R}=C_{D} A_{t h} \sqrt{\rho_{R, l}\left(P_{c}-P_{e}\right)}$.

4 Here, $C_{D}$ is the constant mass flow coefficient. The $A_{t h}$ represents the geometric throat area of the thermostatic expansion, which is adjustable and controlled by the superheat. The $\rho_{R, l}$ is the density of the liquid phase refrigerant. The $P_{c}$ is the condensing pressure, and $P_{e}$ is the evaporating pressure.

\subsection{Heating tower}

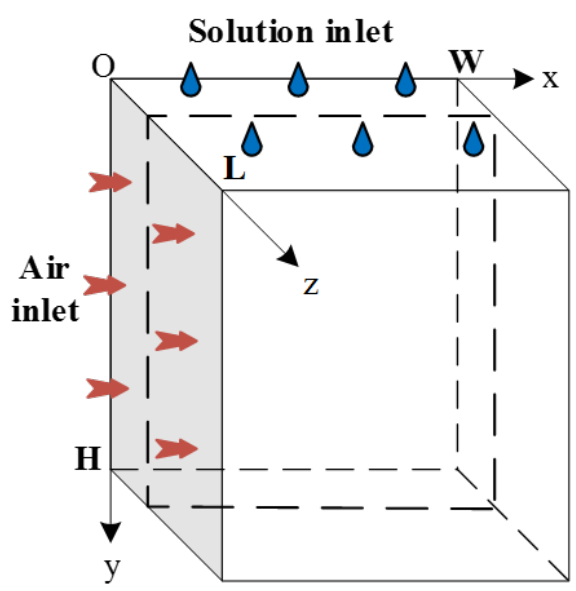

(a) Schematic

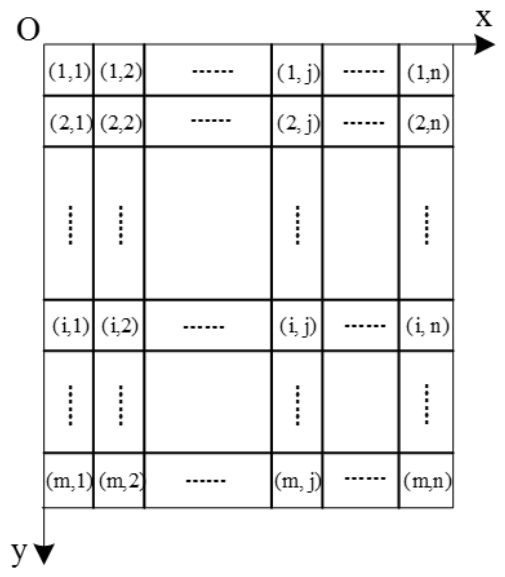

(b)Two-dimensional discretization

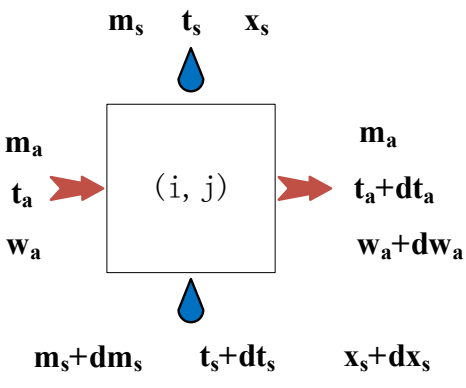

(c) heat and mass transfer of an discretized element

Fig. 3. Discretization process of the cross-flow heating tower

As shown in Fig. 3, this study discretizes the domain of the cross-flow heating tower into small elements using a finite difference method. The convective heat and mass transfer occur in each element are:

$$
\begin{aligned}
& h_{c} L \cdot d x \cdot d y \cdot \alpha_{w}\left(t_{s}-t_{a}\right)=m_{a}\left(C p_{a}+\omega_{a} C p_{v}\right) d t_{a}, \\
& h_{d} L \cdot d x \cdot d y \cdot \alpha_{w}\left(\omega_{s}-\omega_{a}\right)=m_{a} d \omega_{a},
\end{aligned}
$$

where $h_{c}$ is the heat transfer coefficient, $h_{d}$ is the mass transfer coefficient, $\omega_{s}$ is the equivalent humidity ratio of the solution, $d t_{a}$ and $d \omega_{a}$ are the temperature and humidity ratio variation of air through an element, as presented in Fig. 3 (c). The $d x \cdot d y$ represents the size of each element, $\alpha_{w}$ is the specific area of the packing, and $L$ is the length of the packing. The equations of energy, water, and solute balances in each element are:

$$
\begin{aligned}
& m_{a} d h_{a}=-C p_{s} m_{s} d t_{s}-C p_{s} t_{s} d m_{s}, \\
& d m_{s}=-m_{a} d \omega_{a}, \\
& X_{s} m_{s}=\left(X_{s}+d X_{s}\right)\left(m_{s}+d m_{s}\right),
\end{aligned}
$$


where $d h_{a}$ is the enthalpy variation of the air through an element, $X_{S}$ is the mass concentration of the solution. $d t_{s}, d m_{s}$ and $d X_{s}$ represent the variation of the solution in temperature, mass flow rate and concentration, respectively. Heat and mass transfer coefficients are the most important parameters in the heating tower simulation.

The correlation expressions of those two coefficients are expressed as functions of the solution mass flow flux, $G_{s}$, and air mass flow flux, $G_{a}{ }^{[28]}$ :

$$
\begin{aligned}
& h_{c}=4.7600 G_{s}^{0.4289} G_{a}^{0.8678}, \\
& h_{d}=4.8264 G_{s}^{0.4298} G_{a}^{0.8646} .
\end{aligned}
$$

\subsection{Regeneration module}

A regeneration module based on vacuum boiling and condensation is adopted in this study to satisfy the regeneration demand in winter. The adopted module approximates the efficiency of the regeneration system, $\eta_{\text {rege }}$, as a constant of $3.4 \mathrm{~kg} / \mathrm{kWh}^{[21]}$. This is because the performance of this regeneration method is independent of the weather and operating conditions of the HTHP. Then the power input for the regeneration, $W_{\text {rege }}$, can be calculated by the following equation:

$$
W_{\text {rege }}=\frac{3600 Q_{l}}{\eta_{\text {rege }} r_{w}},
$$

where $Q_{l}$ is the latent heat transfer capacity of the heating tower in winter.

\subsection{Fan and pump}

The finned-tube heat exchanger and the heating tower have variable fans, which are controlled by the cooling/heating load of the building. Since the lifting height of air is negligible, the pipeline characteristic curve is a parabola passing through the origin. Therefore, the power of the fan at working point, $W_{f a n}$, is assumed to be proportional to the cubic of the fan speed ratio ${ }^{[29]}$, as shown in Eq. (36):

$$
W_{\text {fan }}=W_{\text {fan, nom }}\left(\frac{N_{\text {fan }}}{N_{\text {fan,nom }}}\right)^{3} \text {, }
$$

where $W_{\text {fan,nom }}$ is the nominal power of the fan. The $N_{\text {fan }}$ is the fan speed, and $N_{\text {fan,nom }}$ is the nominal speed. The tower side pump works with a fixed speed and the power consumption is obtained by the field test, as listed in Table 2.

\subsection{Refrigerant, air, water and solution}

The properties of the refrigerant and water are computed by REFPROP. The thermodynamic properties of air are calculated according to the equations developed by Wang et al. ${ }^{[30]}$. The freezing point, density, kinematic viscosity, thermal conductivity, and specific thermal capacity of glycol aqueous solution are obtained by interpolating the data provided by the ASHRAE handbook ${ }^{[31]}$. In addition to the parameters listed above, the vapor pressure of glycol aqueous, $P_{S}$, is also indispensable in calculating the heat and mass transfer between air and glycol aqueous solution. It can be expressed as ${ }^{[32]}$ : 


$$
\log \frac{P_{S}}{P_{0}}=5.351-6.4 \times 10^{-2} X_{\mathrm{S}}-\frac{1817+0.8 X_{S}\left(100 X_{S}+10\right)}{t_{S}+240},
$$

1 where $P_{0}$ is the pressure of local atmospheric, which is $101.325 \mathrm{kPa}$ in this study. To simplify the calculation, the vapor pressure of solution is often expressed as equivalent humidity ratio ${ }^{[28]}$ :

$$
\omega_{s}=0.622 \frac{P_{S}}{P_{0}-P_{s}} \text {. }
$$

\subsection{System performance indexes}

For both the ASHP and HTHP, the coefficient of performance, COP, is adopted:

$$
C O P=\frac{Q_{e}}{W_{\text {comp }}} \text { for summer and } C O P=\frac{Q_{c}}{W_{\text {comp }}} \text { for winter. }
$$

5 For the entire system, the energy efficiency ratio, EER, considering the power consumption of the fan and pump,

6 is employed. For the ASHP, EER can be expressed as:

$$
E E R=\frac{Q_{e}}{W_{\text {comp }}+W_{f a n, A S H P}} \text { for summer and } E E R=\frac{Q_{c}}{W_{c o m p}+W_{f a n, A S H P}} \text { for winter, }
$$

7 where $W_{f a n, A S H P}$ is the power consumption of the finned-tube heat exchanger fan. For the HTHP, EER is:

$$
E E R=\frac{Q_{e}}{W_{\text {comp }}+W_{\text {fan }, H T H P}+W_{\text {pump }}} \text { for summer and } E E R=\frac{Q_{c}}{W_{\text {comp }}+W_{\text {fan }, H T H P}+W_{\text {pump }}} \text { for winter, }
$$

8 where $W_{\text {fan,HTHP }}$ and $W_{\text {pump }}$ are the power consumption of the heating tower fan and pump, respectively. In order to evaluate the thermodynamic perfectness of the two systems, the second law efficiency, $\eta_{\mathrm{II}}$, is adopted.

$$
\begin{aligned}
& \eta_{\mathrm{II}}=\frac{C O P}{C_{\text {rev }}}, \\
& C O P_{\text {rev }}=\frac{T_{L}}{T_{H}-T_{L}} \text { for summer and } C O P_{\text {rev }}=\frac{T_{H}}{T_{H}-T_{L}} \text { for winter, }
\end{aligned}
$$

where $\mathrm{COP}_{\text {rev }}$ is the efficiency of reverse Carnot cycle. The $T_{L}$ is the temperature of the low-temperature heat source, which is the mean temperature of the inlet and outlet water/solution of the evaporator in this study. The $T_{H}$ is the temperature of the high-temperature heat source, which is the mean temperature of the inlet and outlet air/water of the condenser in this study.

\section{Implementation and validation}

\subsection{Implementation}

The models of the components and fluid mentioned in Section 3 are implemented in the MATLAB environment. Since all the models are non-linear and linked through the input and output parameters, an iterative method is applied to solve the resulted equations. The parameters of the component geometry, weather data, building load, superheating value, mass flow rates of air and water/solution, and solution concentration are considered known under a certain working condition. Since it is difficult to obtain the refrigerant charge of the entire system in practice, subcooling value is treated as a known quantity in order to make the number of equations equal to the number of 
1 the unknowns. In this paper, the superheating and subcooling value are both set as $5^{\circ} \mathrm{C}$. The geometric throat area

2 of the thermal expansion valve is adjusted to make sure that the superheating value reaches its set point. In every

3 condition, the real geometric throat area should be calculated and meet the constraint of its maximum valve. The

4 number of operating compressors $(N)$, the evaporating temperature, condensing temperature, and solution inlet

5 temperature are selected as iteration variables. The initial values of the iteration variables are obtained from the

6 experimental data. In addition, newton iteration is used to update the iteration variables, in order to speed up the

7 convergence of the simulation. In this study, the simulations of the two heat pump systems in both summer and

8 winter conditions were carried out. The computational flowchart for the simulations of the ASHP and HTHP systems

9 in winter conditions is demonstrated in Fig. 4. When calculating their performance in summer, the heating tower subroutine should be linked to the condenser subroutine.

11 In this study, we assume that the dynamic process of the ASHP and HTHP can be represented by multiple 12 steady states since both the weather condition and building's thermodynamic response (e.g. change of building load) 13 are not fast dynamic processes. This approach has been adopted by major building energy simulation tools (e.g. 14 EnergyPlus and DOE-2). Therefore, the stationary models developed in Sections 3 can be used in calculating the 15 energy consumption of the systems in every time interval, which is one-hour in the case study. 


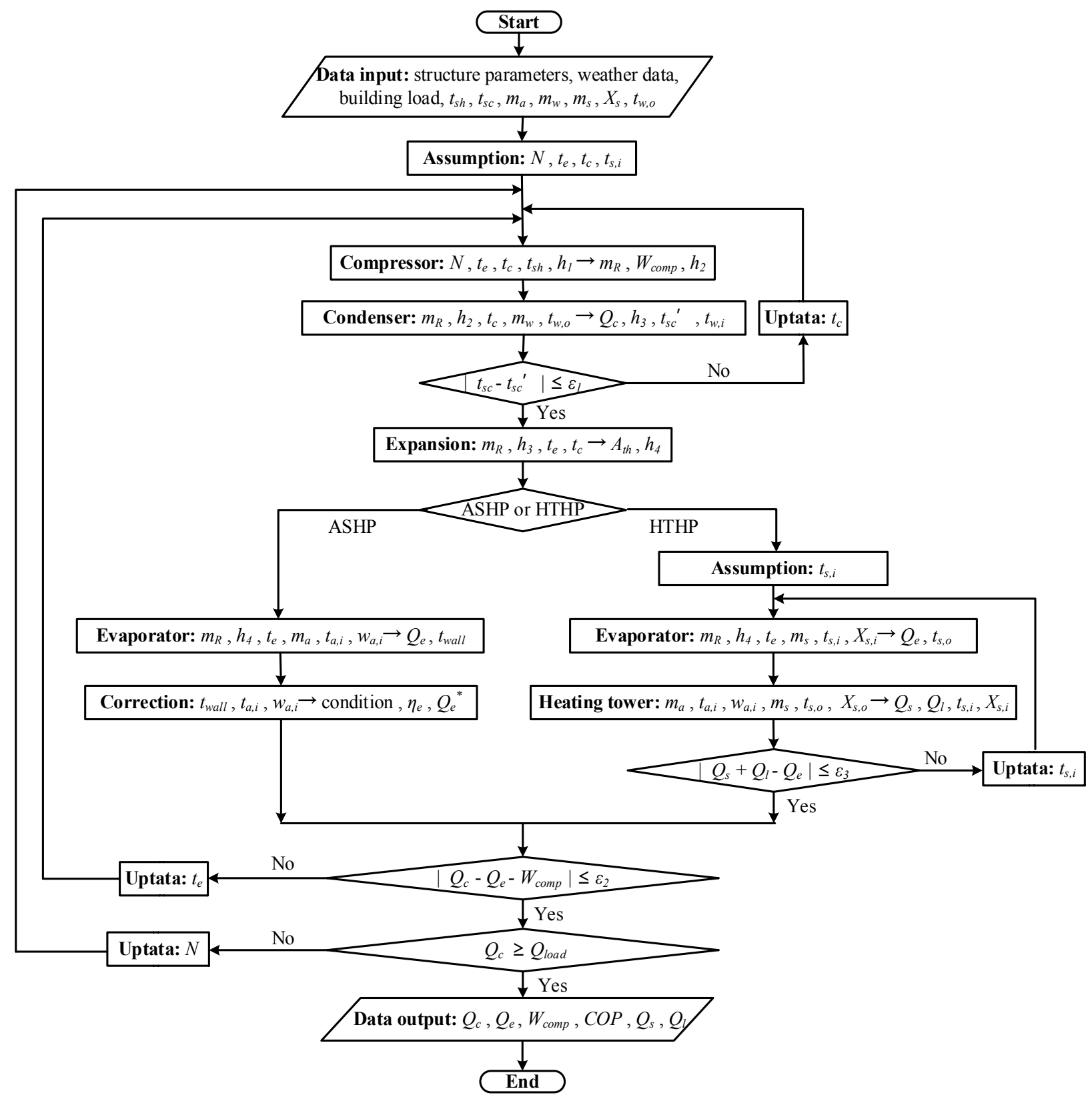

Fig. 4. Scheme of computational flowchart for simulating ASHP and HTHP system in winter condition

\subsection{Validation}

To validate the proposed ASHP model, its results are compared with the results computed by existing software

3 in the market. Here, Solkane (modeling refrigeration cycle) and HTRI (modeling heat exchangers) are adopted and

4 coupled to conduct the validation. As shown in Fig. 5, in the summer condition and winter condition without frosting,

5 the relative difference is within $\pm 10 \%$ with an average difference of $5.94 \%$ for the cooling/heating capacity and

$6 \quad 1.02 \%$ for the COP. In the winter condition with frosting, the relative difference can be more than $10 \%$ since the

7 proposed models added corrections for frosting condition as mentioned in Section 3.3. 


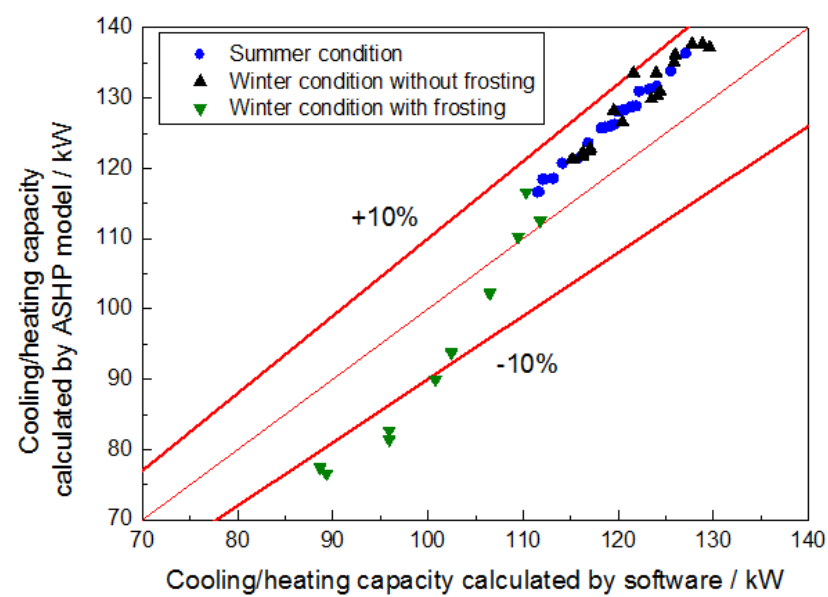

(a) Cooling/heating capacity

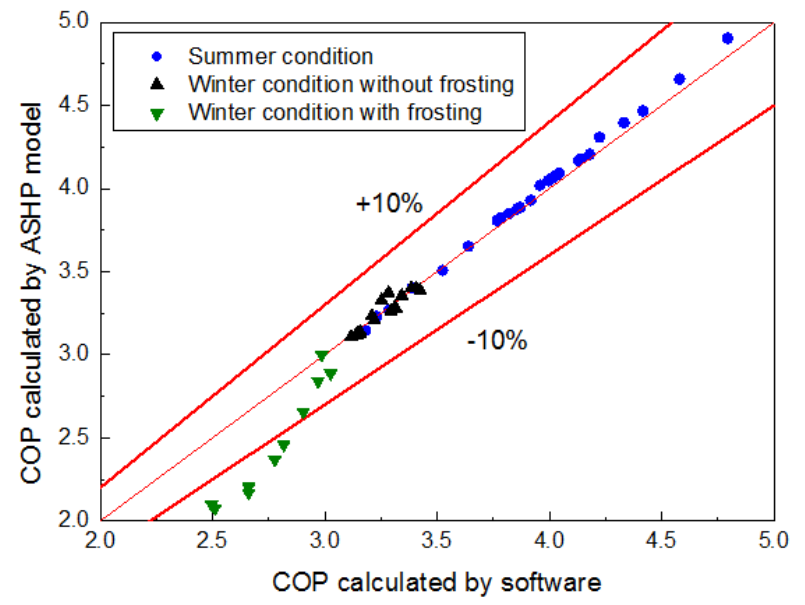

(b) COP

Fig. 5. Comparison between results obtained by the software and the ASHP model

The validation of the HTHP model is presented by comparing the predicted values with our experimental data, including 28 cases under summer condition and 17 cases under winter condition in the typical climate of Nanjing, China. The geometric and operating parameters of the experiments are the same as those indicated in Section 2. As shown in Fig. 6, the relative error is within $\pm 10 \%$ for all cases, and the averaged relative error is $3.48 \%$ for the cooling/heating capacity, and $3.05 \%$ for the COP.

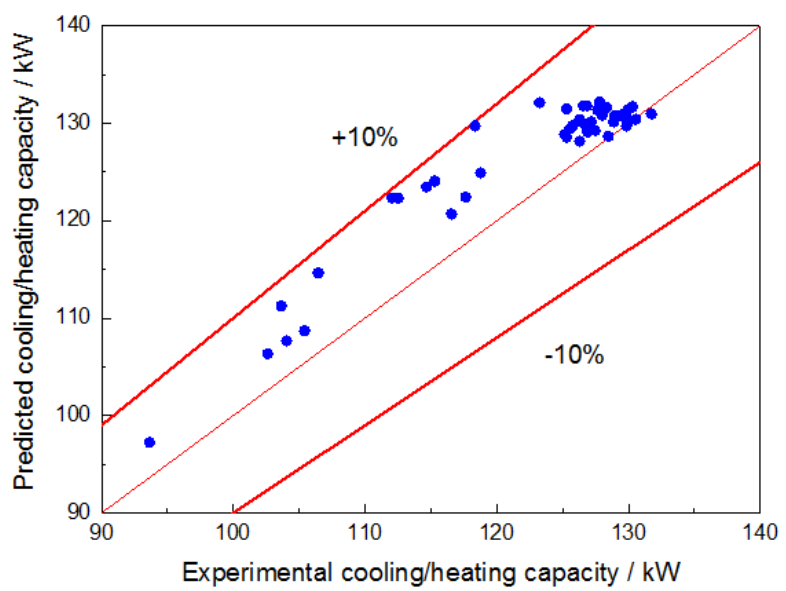

(a) Cooling/heating capacity

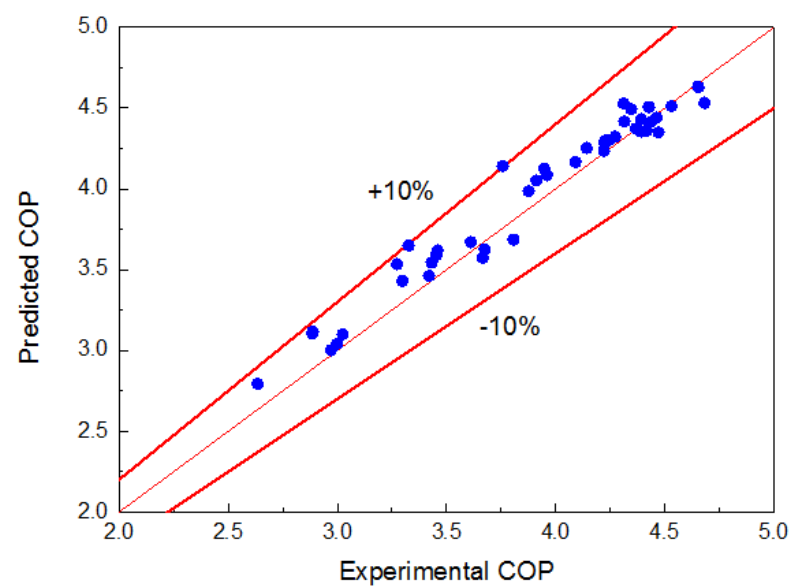

(b) COP

Fig. 6. Comparison between the experimental data and the model prediction of HTHP system

\section{Case study}

Using the validated ASHP and HTHP models, a case study of a four-story office building located in Nanjing, China was carried out. After introducing the case study, we will show the advantages of the comprehensive HTHP model by comparing its COP with the existing approach. Then we will compare the ASHP and HTHP systems by conducting typical day analysis, annual performance analysis, and economic analysis. 


\subsection{Case description}

The office building in our case study has a total floor area of $1,500 \mathrm{~m}^{2}$, and $80 \%$ of that is equipped with the cooling and heating system. The settings of this building are as follows ${ }^{[33]}:$ (1) the cooling season is from May $15^{\text {th }}$ to September $30^{\text {th }}$, and the indoor temperature and humidity setpoints in this season are $24-26^{\circ} \mathrm{C}$ and $40-60 \% \mathrm{RH}$, respectively; (2) the heating season starts from November $15^{\text {th }}$ and lasts to March $15^{\text {th }}$, and the indoor temperature and humidity setpoints are $20-22^{\circ} \mathrm{C}$ and $40-60 \% \mathrm{RH}$, respectively; (3) the schedule of this office building is 08:00 to 18:00 every day; (4) the fresh air rate is $30 \mathrm{~m}^{3} \mathrm{~h}^{-1}$ per person; (5) the occupancy rate is $8 \mathrm{~m}^{2}$ per person. The weather data adopted in this study is taken from the Chinese standard GB 50736-2012 ${ }^{[34]}$. Fig. 7 presents the temperature, relative humidity, and building loads in the simulation hours. The building loads are obtained using the DEST simulation tool. In the cooling season, the peak cooling load is $140.5 \mathrm{~kW}$ with an annual cooling demand of $98,822 \mathrm{kWh}$. And in the heating season, the peak heating load is $115.0 \mathrm{~kW}$ and the annual heating demand is $80,894 \mathrm{kWh}$. The heating capacity of the two systems may not be able to meet the heating demand in some extreme cold days. In this case, an electric auxiliary heater is adopted to meet the heating demand.

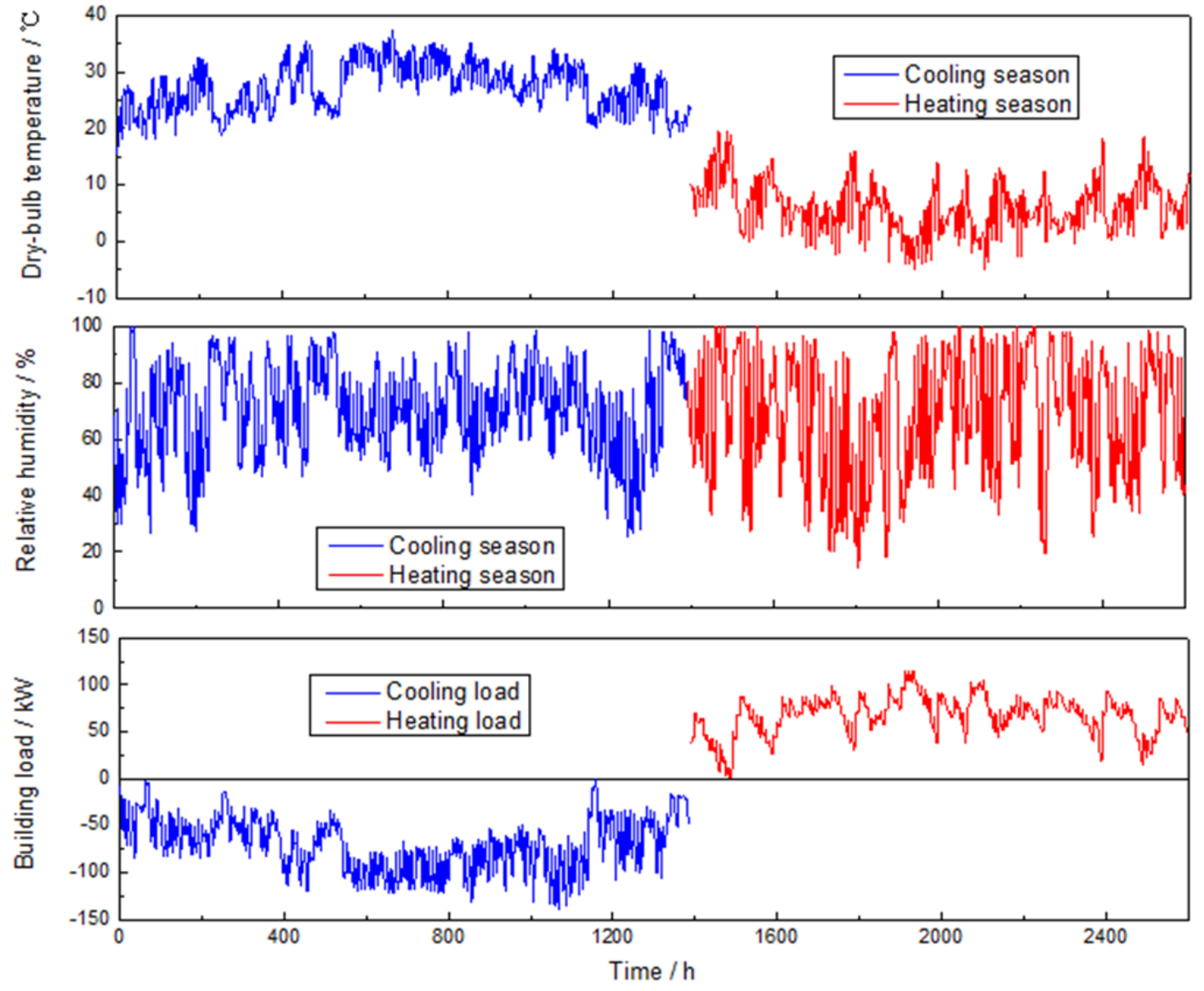

Fig. 7. Weather data and building load in the simulation hours 


\subsection{Results and discussion}

\subsubsection{Evaluation of the comprehensive HTHP model}

To evaluate the impact of regeneration module and summer performance, we compare the HTHP model with and without the regeneration module, as well as their COP in both summer and winter. The annual COP is the total cooling and heating capacities divided by the annul power consumption and the results are presented in Table 6 . Taking the performance of the ASHP as baseline, the HTHP shows a bigger energy saving potential in summer (23.1\%) than in winter (7.4\%). Therefore, when evaluating the performance of HTHP system, it is necessary to include its summer performance, which was ignored in the previous studies ${ }^{[15-19]}$. In winter, the COP of the HTHP without regeneration has an increase of $15.2 \%$ compared with the ASHP. However, the COP increase is about $7.4 \%$ when considering the energy consumption of regeneration. Considering the regeneration will lead to a difference of $7.8 \%$ in COP in the winter. However, due to the relatively low annual heating demand in Nanjing (compared with annual cooling demand), this will only lead to a difference of $4.4 \%$ in the annual COP (3.91 vs. 3.78). The impact of regeneration may be larger if the HTHP system is applied in the region with higher heating demand than Nanjing, such as Wudu, which is in the north of the mixed climate zones. Thus, in the following section, the HTHP model with the regeneration module is used for the comparison.

Table 6. The comparison of HTHP models

\begin{tabular}{|l|l|l|l|}
\hline System performance & ASHP & HTHP without regeneration & HTHP with regeneration \\
\hline COP in summer & 3.79 & 4.66 & 4.66 \\
\hline COP in winter & 2.84 & 3.27 & 3.05 \\
\hline Annual COP & 3.29 & 3.91 & 3.78 \\
\hline
\end{tabular}

\subsubsection{Typical day analysis between ASHP and HTHP}

Performance analysis of the ASHP and HTHP systems on a typical day in summer (July $30^{\text {th }}$ ) and a typical day in winter (January $26^{\text {th }}$ ) were carried out to investigate the difference in their operating mechanisms. The weather data of these two days are shown in Fig. 8.
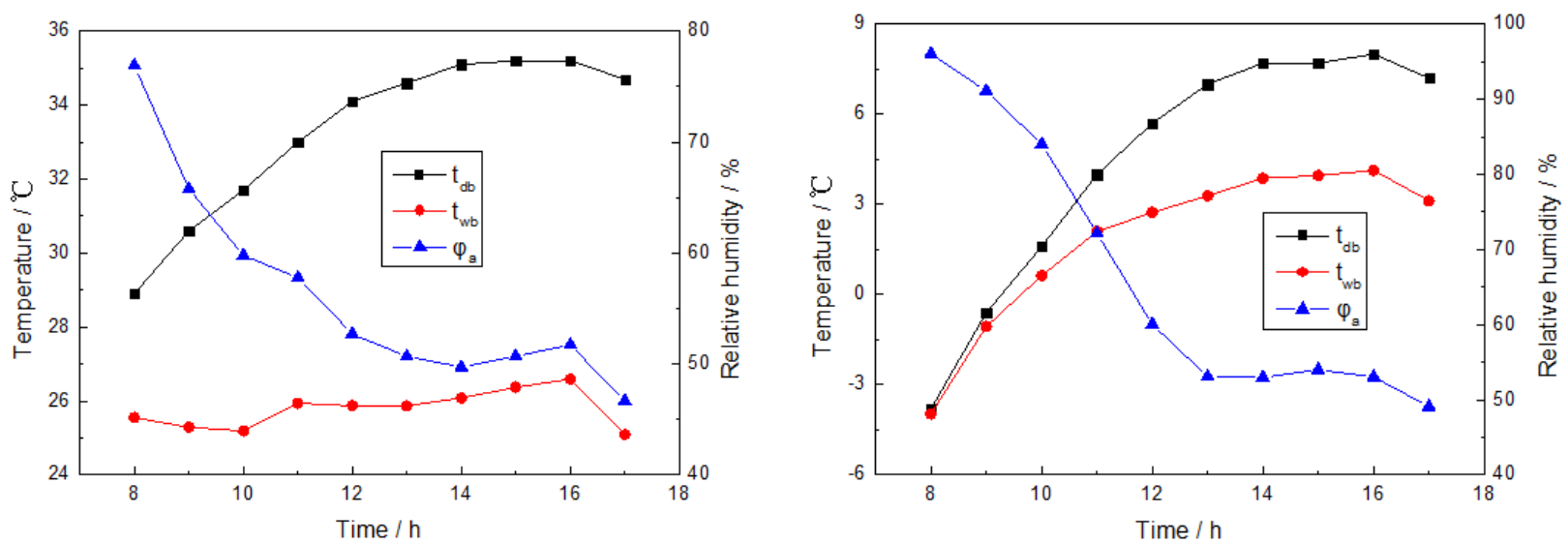

(a) summer
(b) winter

Fig. 8. Weather data of the typical days in Nanjing, China

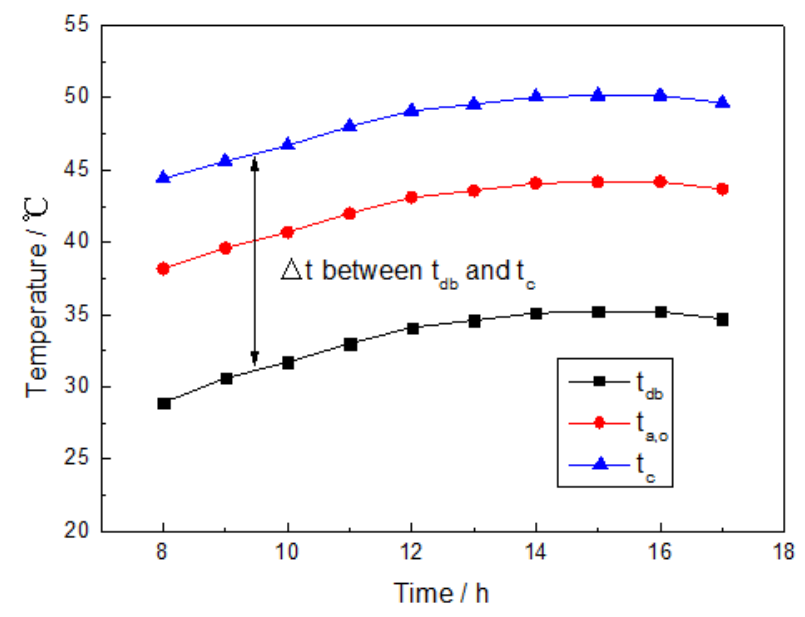

(a) ASHP

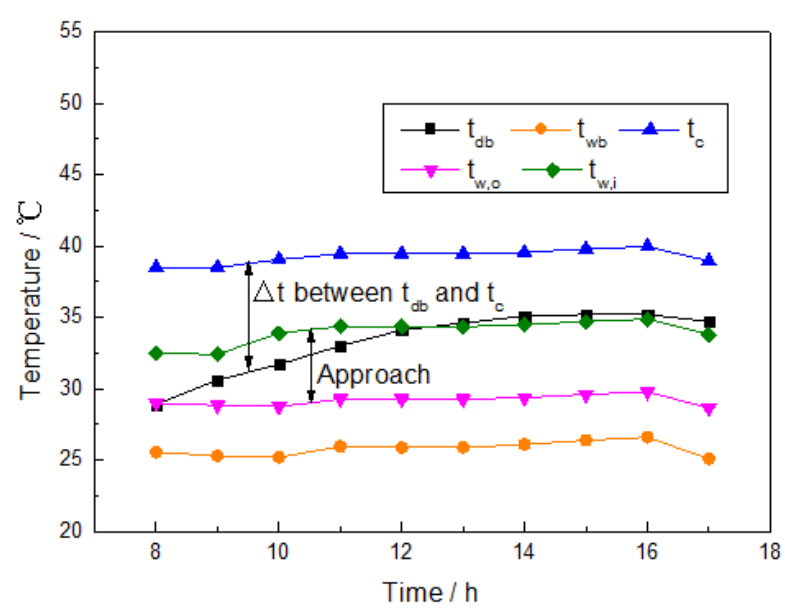

(b) HTHP

Fig. 9. Operating data comparison of ASHP and HTHP in the typical day in summer 


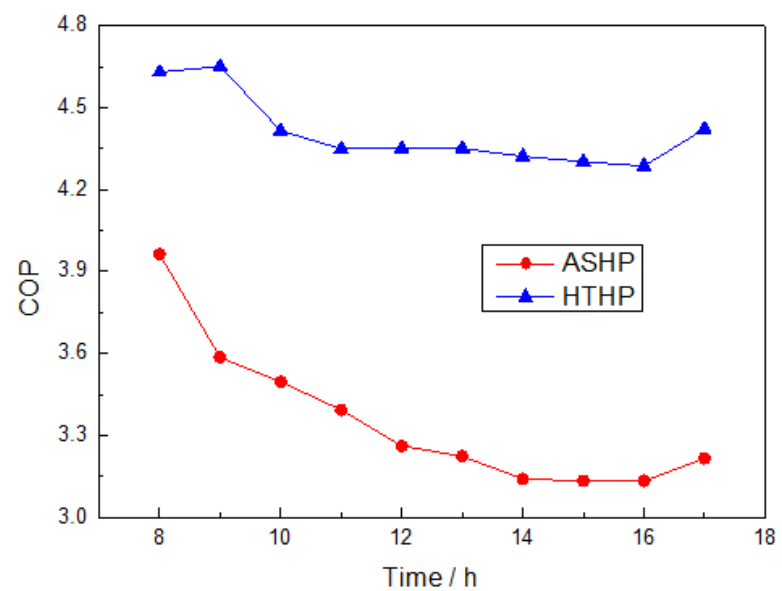

(a) COP

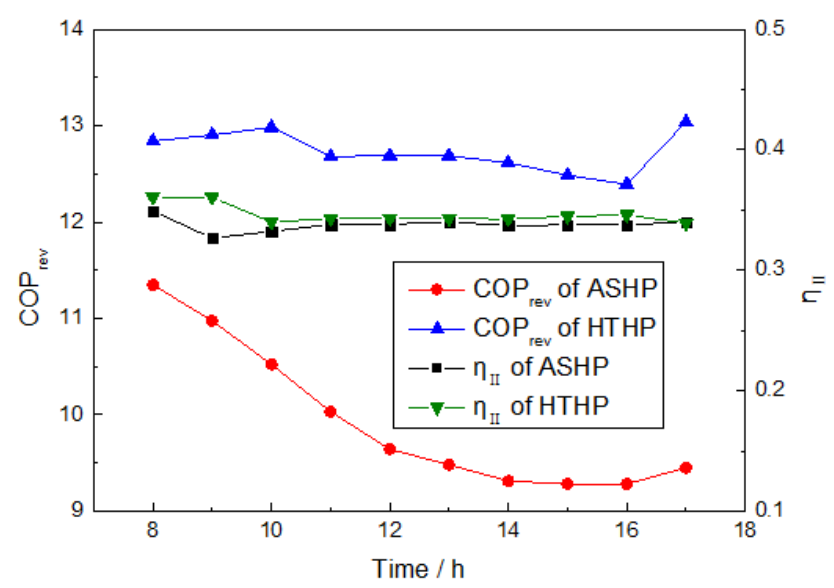

(b) $\mathrm{COP}_{\mathrm{rev}}$ and $\eta_{\mathrm{II}}$

Fig. 10. Performance comparison of the ASHP and HTHP in the typical day in summer

The operating data of the ASHP in the typical day in winter are presented in Fig. 11. From about 8:00 to 13:00, frosting occurs in the ASHP and the mean difference between the ambient dry-bulb, $t_{d b}$ and evaporating temperature, $t_{e}$, is $14.5^{\circ} \mathrm{C}$ (Fig. 11a). This leads to up to $20 \%$ reduction in both efficiency and heating capacity. Correspondingly, the correction coefficient, $\eta$, is less than 1 as shown in Fig. 11 (b). For the HTHP, when the drybulb temperature is low and relative humidity is high, the heating tower can still heat the solution to approximately $2.7^{\circ} \mathrm{C}$ below the ambient wet-bulb temperature by exchanging heating with ambient air (sensible heat transfer) and absorbing water vapor (latent heat transfer). This makes the difference between $t_{d b}$ and $t_{e}$ to be about $9.3^{\circ} \mathrm{C}$ (Fig. 12a). As a result, the HTHP system efficiency and heating capacity stable in such severe operating conditions. In those conditions, the HTHP shows much higher efficiency than the ASHP, as presented in Fig. 13.

As the air temperature rises and relative humidity drops, the ASHP runs without frosting after 13:00. The mean difference between $t_{d b}$ and $t_{e}$ of the ASHP is $12.2^{\circ} \mathrm{C}$. Relatively, this mean difference for HTHP over the same period is $11.6^{\circ} \mathrm{C}$, as presented in Fig. 12(a). As a result, the COPs of the ASHP and the HTHP under those nofrosting conditions are quite close, as shown in Fig. 13(a). As mentioned early, the HTHP needs to evaporates excessive water, which may be absorbed in the early morning, from the solution to ambient air to maintain the concentration of the solution. This solution regeneration process will reject latent heat to the atmosphere and require additional energy input. Fortunately, the HTHP tower will evaporate the excessive water in the afternoon as a byproduct of tower-heating process and this process can be called "self-regeneration process". The self-regeneration process occurs in from 13:00 to 17:00 as shown in Fig. 12(b), which can reduce the energy consumption of the regeneration system. However, there are $59.9 \mathrm{~kg}$ water need to be evaporated, which will cost $17.6 \mathrm{kWh}$ by the regeneration system. Considering the regeneration and frosting conditions of the typical day, the HTHP achieves an increase of $12.8 \%$ in efficiency (COP) compared to the ASHP.

The comparison of the reverse Carnot cycle efficiency $\left(C O P_{r e v}\right)$ and second law efficiency $\left(\eta_{I I}\right)$ between the ASHP and HTHP is presented in Fig. 13(b). To conduct the heat absorption, the temperature of the solution is lower 
1 than the outdoor air. Thus, the HTHP shows lower $C O P_{r e v}$ due to lower $T_{L}$. Combining with the analysis of $C O P$,

2 the HTHP has higher $\eta_{I I}$ than the ASHP, as shown in Fig. 13(b).

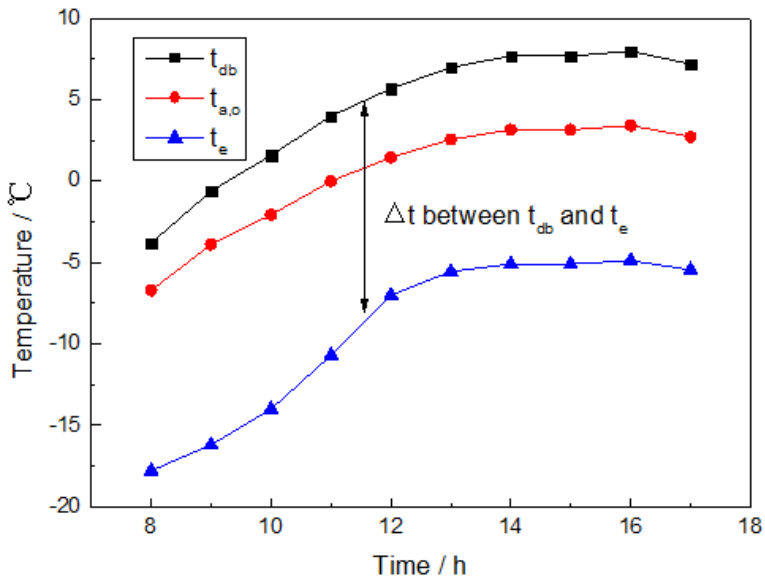

(a) Temperature distribution

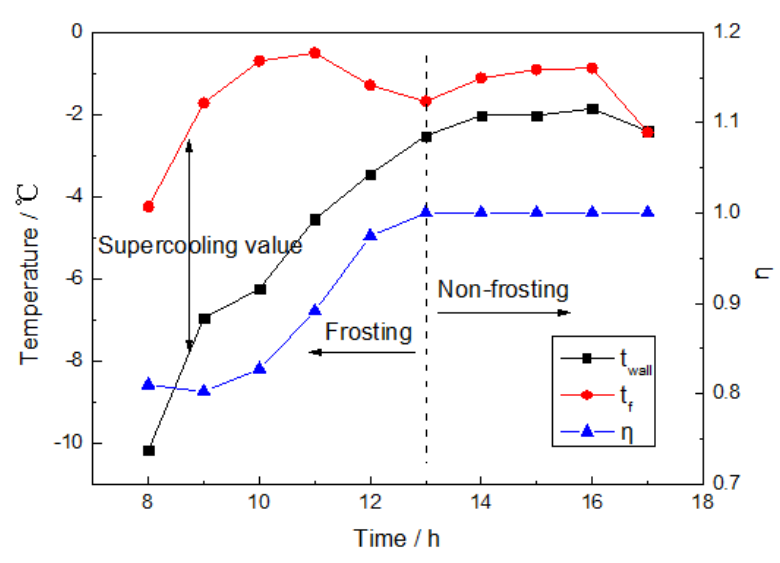

(b) Frosting conditions

Fig. 11. Operating parameters of the ASHP in the typical day in winter

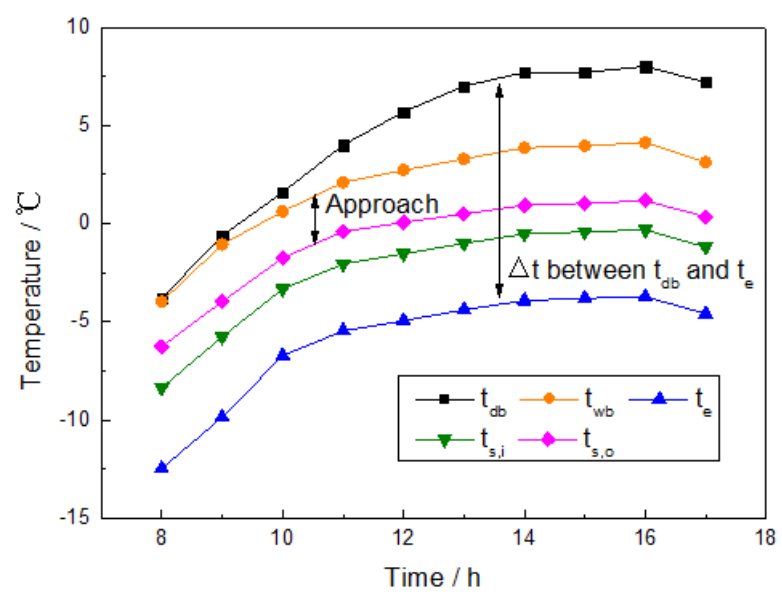

(a) Temperature distribution

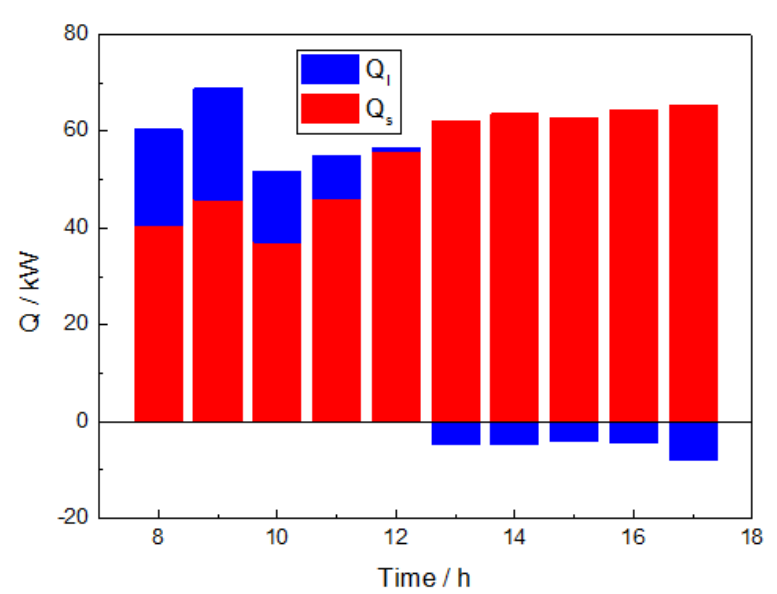

(b) Sensible and latent heat

Fig. 12. Operating parameters of the HTHP in the typical day in winter

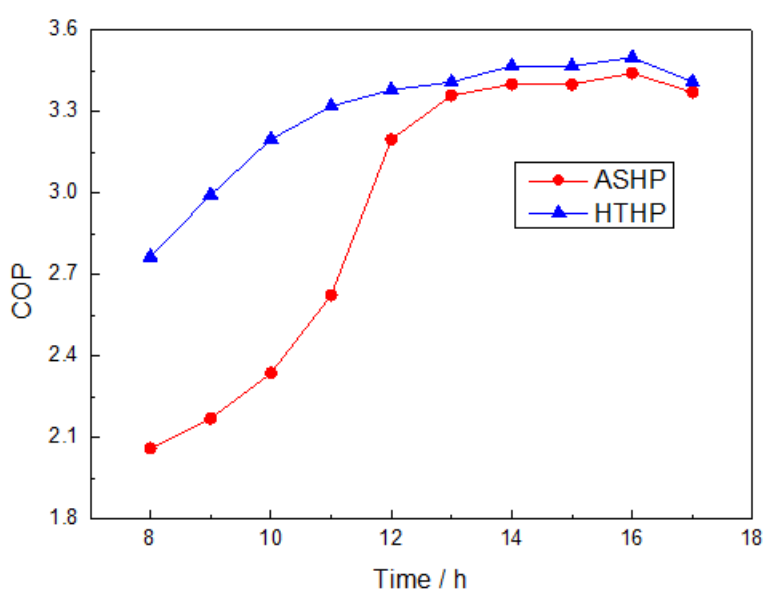

(a) $\mathrm{COP}$

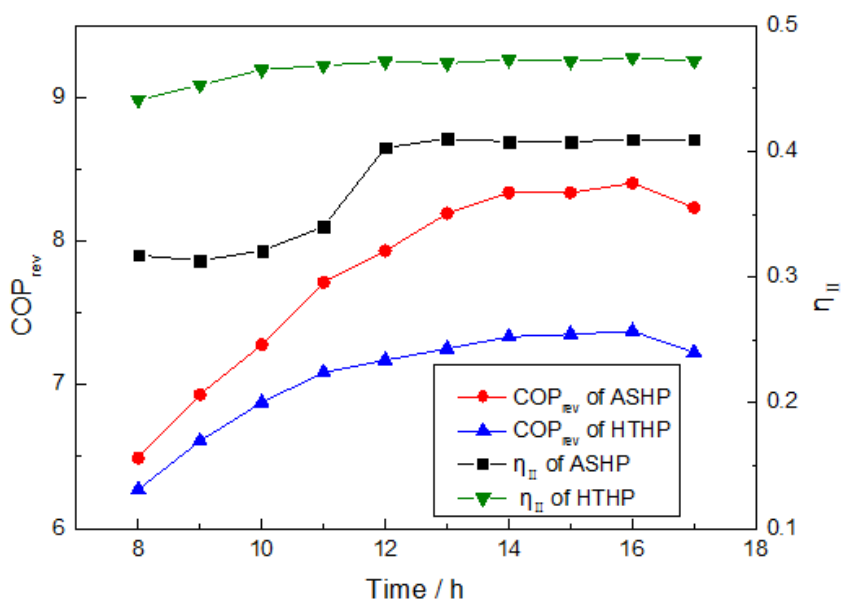

(b) $\mathrm{COP}_{\text {rev }}$ and $\eta_{\mathrm{II}}$ 
Fig. 13. Performance comparison of ASHP and HTHP in the typical day in winter

To further demonstrate the differences between the ASHP and HTHP, T-s diagrams of these two systems in typical conditions (14:00 in the typical summer day, 11:00 in the typical winter day) are presented. As shown in Fig. 14 (a), the evaporating temperature of the ASHP is same as that of the HTHP in summer. Since the parameters of the chilled water and the evaporator of the two systems are the same. Due to the water-cooled approach, the condensing temperature of the HTHP is $10^{\circ} \mathrm{C}$ lower than the ASHP. As a result, the HTHP has higher cooling capacity and lower energy consumption for unit flow refrigerant. For the typical winter condition, the condensing temperatures of the HTHP and ASHP are the same, as shown in Fig. 14 (b). However, the HTHP can take advantage of both sensiable and latent heat from the air, and have higher evaporating temperature $\left(5^{\circ} \mathrm{C}\right)$ than the ASHP, which has frosting issue in this condition. So, the energy consumption for unit flow refrigerant of ASHP is higher than the HTHP.

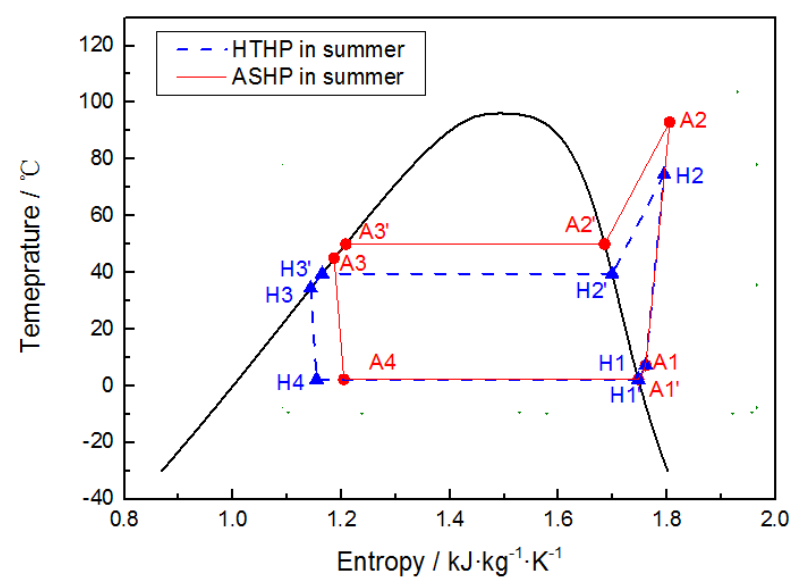

(a) Summer

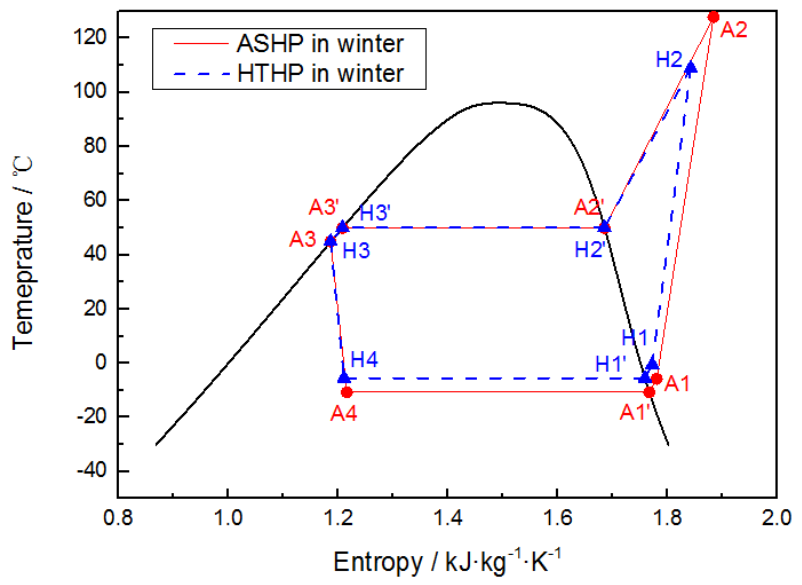

(b) Winter

Fig. 14. T-s diagrams of ASHP and HTHP

\subsubsection{Annual performance analysis}

In order to obtain the annual performance of the ASHP and the HTHP, hourly simulations of both systems were carried out. As discussed in Table 6, the annual COP of the ASHP is 3.29, and it is 3.78 for the HTHP. The following will explain the annual performance difference by analysis their performance in the summer and winter conditions.

In the summer conditions, the HTHP shows higher efficiency than the ASHP in every simulation hour as presented in Fig. 15. The average COPs are 4.66 for the HTHP and 3.79 for the ASHP. The $23.1 \%$ COP increase is achieved by HTHP mainly due to using the water-cooled method instead of the air-cooled method as discussed in Section 5.2.2. 


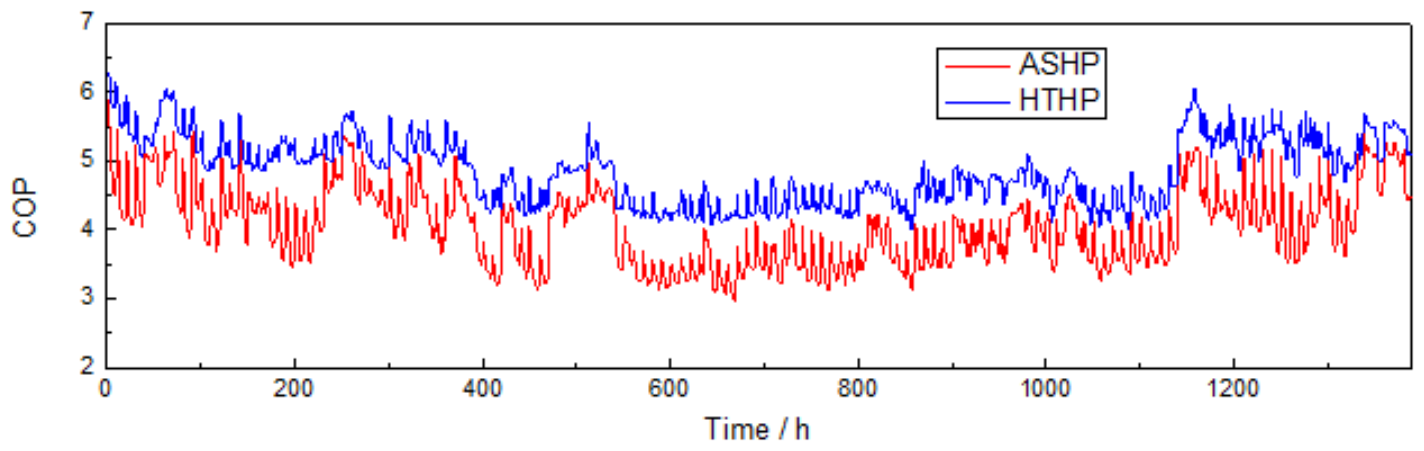

Fig. 15. Performance comparison of ASHP and HTHP in summer condition

The operating conditions of ASHP in winter is plotted in the frosting map (Fig. 16). The ratios of operating conditions in the four zones are $33.1 \%, 21.1 \%, 26.2 \%$, and $19.6 \%$, respectively. In the $45.8 \%$ of the winter operation hours, the ASHP is under frosting conditions (Zone III and $I V$ ). As a result, the efficiency of the ASHP reduces significantly. Even worse, the ASHP cannot satisfy the heating demand for 109 hours due to the frosting issue. The unsatisfied heating demand of $999 \mathrm{kWh}$ needs to be provided by an auxiliary electric heater. For the HTHP, 38.7\% of the operating hours is under regeneration condition. For the rest hours, water condenses into the system as demonstrated in Fig. 17. As a result, $6,064 \mathrm{~kg}$ of water need to be evaporated to protect the solution from dilution. A vacuum boiling with condensation method was adopted to satisfy the demand of regeneration in this study, as indicated in Section 3.6. Totally, 1,784 kWh power is consumed by the regeneration system. By taking both frosting and regeneration into account, the performance comparison of the ASHP and HTHP in winter condition is obtained, as presented in Fig. 18. In the non-frosting hours, the COPs of the ASHP and HTHP are quite close. In the severe operating conditions, the HTHP shows higher and more stable efficiency than the ASHP due to the energy storage of the solution (absorbing latent heat in the cold and humid hours, and self-regeneration in the warm hours). The average COP of the HTHP is 3.05, and that of the ASHP is 2.84. A 7.4\% increase is achieved by the HTHP. Furthermore, the HTHP can solve the frosting issue and guarantee the heating capacity. 


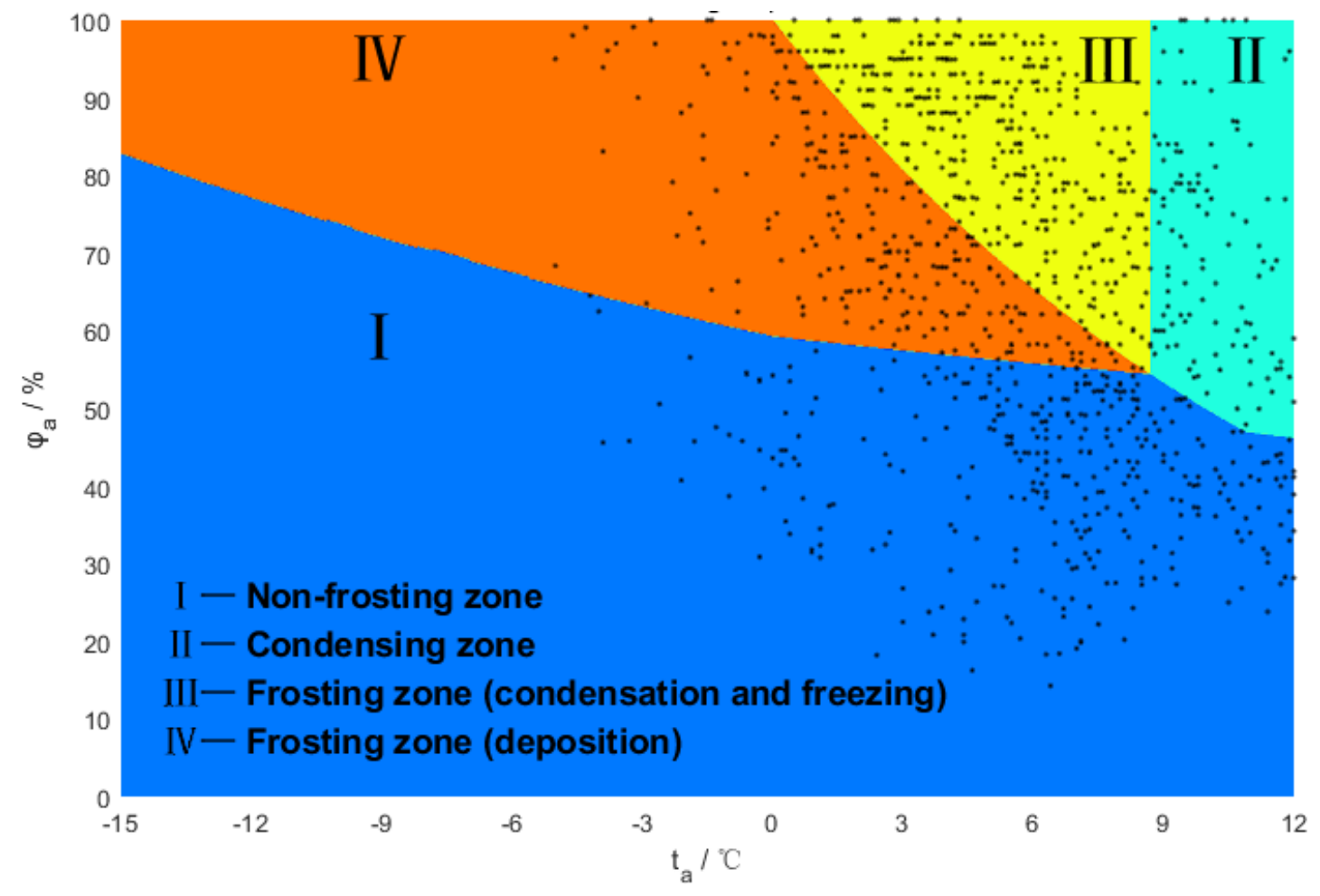

Fig. 16. Frosting map and operating conditions distribution of ASHP

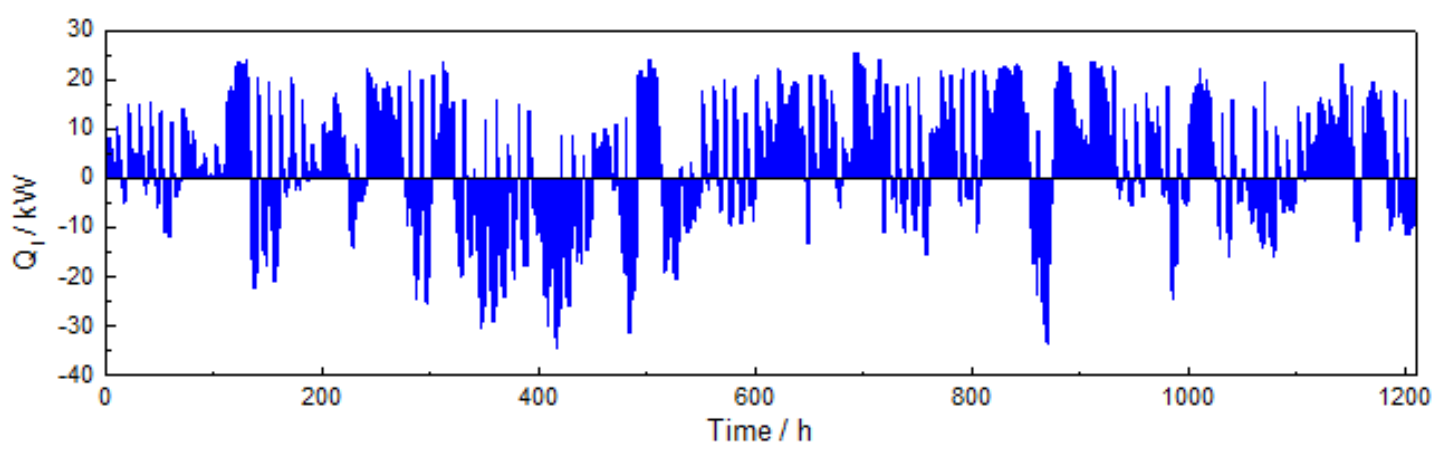

Fig. 17. Latent heat transfer capacity of heating tower in winter condition

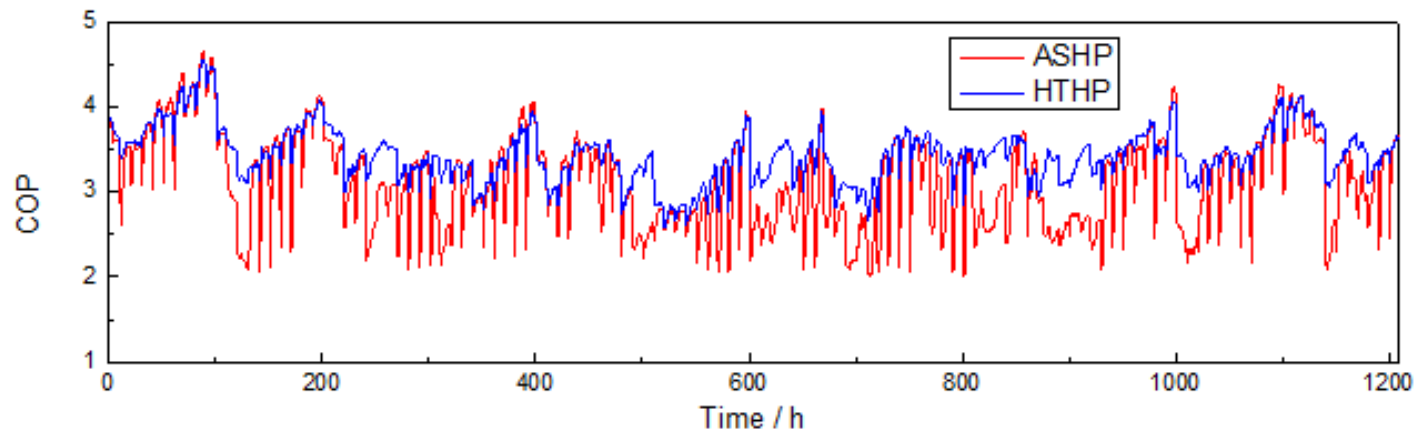

Fig. 18. Performance comparison of ASHP and HTHP in winter condition 


\subsubsection{Economic analysis}

An economic analysis is performed for both ASHP and HTHP. Initial costs of the components and system power consumption are considered, as well as the costs of solution for the HTHP. Maintenance costs are not considered, as equal maintenance is assumed for both heat pump systems. All the prices used here are taken from practical projects. Since this simulation work is performed for an office building in Nanjing, the electricity rate of Nanjing in 2017 is adopted. The rate is a constant price at 0.8366 Chinese Yuan per kWh. Electricity consumption of each year is converted to current Yuan and then summed up for 10 years. Then this is combined with the initial cost of year 0 to develop a total cost in present yuan. The discount rate used in this process is $4.9 \%$ according to the Bank of China in 2017.

Table 7 demonstrates the details of the economic analysis. Though the initial cost of the HTHP is $1.2 \%$ higher than that of the ASHP, the annual power consumption of the HTHP is 13.1\% lower. As a result, the 10-year cost of the ASHP is 9.7\% higher than the HTHP.

Table 7. 10-year cost of ASHP and HTHP

\begin{tabular}{|c|c|c|c|c|c|}
\hline \multirow{2}{*}{ System } & \multirow{2}{*}{ Component } & Initial cost & Power consumption & Annual operating cost & 10 -year cost \\
\hline & & $10^{3}$ yuan & $\mathrm{kWh}$ & $10^{3}$ yuan & $10^{3}$ yuan \\
\hline ASHP & Heat pump & 108.0 & $\begin{array}{c}28,970 \text { (summer) } \\
30,760 \text { (winter) }\end{array}$ & 50.0 & 495.7 \\
\hline \multirow{5}{*}{ HTHP } & Heat pump & 72.0 & \multirow{5}{*}{$\begin{array}{c}22,854 \text { (summer) } \\
29,940 \text { (winter) }\end{array}$} & \multirow{5}{*}{44.2} & \multirow{5}{*}{452.0} \\
\hline & Heating tower & 14.8 & & & \\
\hline & Tower side pump & 3.5 & & & \\
\hline & Regeneration system & 15.0 & & & \\
\hline & Glycol aqueous & 4.0 & & & \\
\hline
\end{tabular}

\section{Conclusion}

The HTHPs are taken as an alternative to the conventional ASHPs for heating and cooling supply. The HTHPs have some advantages comparing to the ASHPs, particularly in terms of efficiency and no-frosting. In this study, detailed models of these two heat pump systems were developed and hourly simulations were carried out to compare the performance of the HTHP versus the ASHP in an office building in Nanjing, China. Further, an economic analysis was performed to account for the differences between the initial and a 10-year operating costs of the two systems. According to the results of the present economic and technical analysis, the following conclusions have been drawn:

(1) The HTHP shows a bigger energy saving potential in summer $(23.1 \%)$ than in winter $(7.4 \%)$. The winter efficiency increases of the HTHP with and without regeneration are $7.4 \%$ and $15.2 \%$. As a conclusion, it is necessary to consider both summer performance and winter regeneration when calculating the performance of the HTHP in warm and mixed climate zones of the world. 
1 (2) The HTHP is about $32.7 \%$ more efficient than ASHP in a typical summer day and $12.8 \%$ more efficient in a 2 typical winter day.

3 (3) In summer, the average COP of the HTHP is 4.66, and that of the ASHP is 3.79. A 23.1\% increase in COP is achieved by the HTHP because of the water-cooled approach. In winter, the average COP of the HTHP is 3.05, and that of the ASHP is 2.84, which represent a 7.4\% increase in COP. And the HTHP shows more stable efficiency than the ASHP under severe operating conditions due to the energy storage of the solution.

7 (4) Although the initial costs of the HTHP are 1.2\% higher than that of the ASHP, the annual power consumption of the HTHP is $13.1 \%$ lower. As a result, the HTHP can save $9.7 \%$ cost in a 10 -year period.

\section{Acknowledgement}

The research described in this paper is supported by the National Natural Science Foundation of China (No. 51520105009), the China National Key R \& D Program (No. 2016YFC0700305), and the Scientific Research Foundation of Graduate School of Southeast University (No. YBJJ1708). The researchers in the US are supported by the National Science Foundation (No. IIS-1802017).

Nomenclature

\begin{tabular}{|c|c|c|c|}
\hline$A$ & heat exchange area, $\mathrm{m}^{2}$ & $\begin{array}{l}\text { Greek } \\
\text { symbols }\end{array}$ & \\
\hline Ath & geometric throat area of thermostatic expansion, $\mathrm{m}^{2}$ & $\alpha_{w}$ & specific area of the packing, $\mathrm{m}^{2} \mathrm{~m}^{-3}$ \\
\hline$b$ & width of fin, $m$ & $\beta$ & regression coefficient of Eq. (2) \\
\hline$C_{D}$ & constant mass flow coefficient & $\Delta t$ & logarithmic temperature difference, ${ }^{\circ} \mathrm{C}$ \\
\hline$C_{p}$ & specific heat at constant pressure, $\mathrm{kJ} \mathrm{kg}^{-1} \mathrm{~K}^{-1}$ & $\varepsilon$ & correction factor \\
\hline$c$ & regression coefficient & $\eta$ & efficiency \\
\hline$d$ & diameter of tube, $\mathrm{m}$ & $\lambda$ & thermal conductivity coefficient, $\mathrm{W} \mathrm{m}^{-1} \mathrm{~K}^{-1}$ \\
\hline$G$ & mass flow flux, $\mathrm{kg} \mathrm{m}^{-2} \mathrm{~s}^{-1}$ & $\pi$ & regression coefficient of Eq. (1) \\
\hline$h$ & enthalpy, $\mathrm{kJ} \mathrm{kg}^{-1}$ & $\rho$ & density, $\mathrm{kg} \mathrm{m}^{-3}$ \\
\hline$h_{c}$ & heat transfer coefficient of tower, $\mathrm{W} \mathrm{m}^{-2} \mathrm{~K}^{-1}$ & $\Psi$ & correction factor \\
\hline$h_{d}$ & mass transfer coefficient of tower, $\mathrm{g} \mathrm{m}^{-2} \mathrm{~s}^{-1}$ & $\omega$ & humidity ratio, $\mathrm{kg} \mathrm{kg}^{-1}$ \\
\hline K & $\begin{array}{l}\text { heat transfer coefficient of heat exchanger, } \mathrm{W} \mathrm{m}^{-2} \\
\mathrm{~K}^{-1}\end{array}$ & $\xi$ & coefficient of Eq. (23) \\
\hline$L$ & length of the packing, $\mathrm{m}$ & $T$ & coefficient of Eq. (25) \\
\hline Le & Lewis number, / & Subscript & \\
\hline$m$ & mass flow rate, $\mathrm{kg} \mathrm{s}^{-1}$ & $a$ & air \\
\hline$N$ & number of operating compressors & $c$ & condenser \\
\hline$P$ & pressure, $\mathrm{Pa}$ & comp & compressor \\
\hline$P_{0}$ & pressure of local atmospheric, $\quad 101.325 \mathrm{kPa}$ & $d p$ & dew point \\
\hline $\operatorname{Pr}$ & Prandtl number, / & $e$ & evaporator \\
\hline
\end{tabular}




\begin{tabular}{|l|l|l|l|}
\hline$P_{s}$ & water vapor pressure of solution, $\mathrm{kPa}$ & $f$ & freezing point \\
\hline$Q$ & heat transfer capacity, kW & $f a n$ & $\begin{array}{l}\text { fan of heating tower or finned-tube heat } \\
\text { exchanger }\end{array}$ \\
\hline$q$ & heat flux, $\mathrm{W} \mathrm{m}{ }^{-2}$ & $g$ & gas phase \\
\hline$Q_{l}$ & latent heat transfer capacity of heating tower, $\mathrm{kW}$ & $i$ & inlet or inner \\
\hline$Q_{s}$ & sensible heat transfer capacity of heating tower, $\mathrm{kW}$ & $l$ & liquid phase \\
\hline$R$ & Resistance of heat transfer, $\mathrm{m}^{2} \mathrm{~K} \mathrm{~W}^{-1}$ & $N$ & rotational speed, rpm \\
\hline$r$ & vaporization latent heat, $\mathrm{kJ} \mathrm{kg}^{-1}$ & $o$ & outlet or external \\
\hline$R e$ & Reynolds number, / & $R$ & refrigerant \\
\hline$T$ & temperature, K & rege & regeneration \\
\hline$t$ & temperature, ${ }^{\circ} \mathrm{C}$ & $s$ & solution \\
\hline$u$ & dynamic viscosity, $\mathrm{N} \mathrm{s} \mathrm{m}{ }^{-2}$ & $t h$ & throat of thermostatic expansion \\
\hline$v$ & suction specific volume of compressor, $\mathrm{m}^{3} \mathrm{~kg}^{-1}$ & $v$ & vaper \\
\hline$W$ & power consumption, $\mathrm{kW}$ & $w$ & water \\
\hline$X$ & mass concentration of solution, / & wall & wall of tube \\
\hline$x$ & dryness of refrigerant, / & \\
\hline
\end{tabular}

\section{References}

[1] Ansi/Ashrae. ANSI/ASHRAE Standard 169-2013, Climatic Data for Building Design Standards [S].American Society of Heating, Refrigerating and Air-Conditioning Engine, 2013.

[2] Yu F W, Chan K T. Improved energy performance of air cooled centrifugal chillers with variable chilled water flow [J]. Energy Conversion and Management, 2008, 49: 1595-1611.

[3] Zhu J, Sun Y, Wang W, et al. Developing a new frosting map to guide defrosting control for air-source heat pump units [J]. Applied Thermal Engineering, 2015, 90: 782-791.

[4] Kim M-H, Kim H, Lee K-S, et al. Frosting characteristics on hydrophobic and superhydrophobic surfaces: A review [J]. Energy Conversion and Management, 2017, 138: 1-11.

[5] Song M, Pan D, Li N, et al. An experimental study on the negative effects of downwards flow of the melted frost over a multi-circuit outdoor coil in an air source heat pump during reverse cycle defrosting [J]. Applied Energy, 2015, 138: 598-604.

[6] Kim M-H, Kim H, Kim D R, et al. A novel louvered fin design to enhance thermal and drainage performances during periodic frosting/defrosting conditions [J]. Energy Conversion and Management, 2016, 110: 494-500.

[7] Su W, Li W, Zhang X. Simulation analysis of a novel no-frost air-source heat pump with integrated liquid desiccant dehumidification and compression-assisted regeneration [J]. Energy Conversion and Management, 2017, 148: 1157-1169.

[8] Su W, Li W, Zhou J, et al. Experimental investigation on a novel frost-free air source heat pump system combined with liquid desiccant dehumidification and closed-circuit regeneration [J]. Energy Conversion and Management, 2018, 178: 13-25.

[9] Fujita T, Kawahara K. Thermal characteristics of heating towers [J]. Transactions of the Japan Society of Refrigerating and Air Conditioning Engineers, 2012, 6: 275-284.

[10] Tan K, Deng S. A method for evaluating the heat and mass transfer characteristics in a reversibly used water cooling tower (RUWCT) for heat recovery [J]. International journal of refrigeration, 2002, 25: 552-561. 
[11] Zhang Q, Wu J, Zhang G, et al. Calculations on performance characteristics of counterflow reversibly used cooling towers [J]. International Journal of Refrigeration, 2012, 35(2): 424-433.

[12] Wen X, Liang C, Zhang X. Experimental study on heat transfer coefficient between air and liquid in the crossflow heat-source tower [J]. Building and Environment, 2012, 57: 205-213.

[13] $\mathrm{Lu} \mathrm{J,} \mathrm{Li} \mathrm{W,} \mathrm{Li} \mathrm{Y,} \mathrm{et} \mathrm{al.} \mathrm{Numerical} \mathrm{study} \mathrm{on} \mathrm{heat} \mathrm{and} \mathrm{mass} \mathrm{transfer} \mathrm{characteristics} \mathrm{of} \mathrm{the} \mathrm{counter-flow} \mathrm{heat-source}$ tower (CFHST) [J]. Energy and Buildings, 2017, 145: 318-330.

[14] Song P, Wang B, Li X, et al. Experimental research on heat and mass transfer characteristics of cross-flow closedtype heat-source tower [J]. Applied Thermal Engineering, 2018, 135: 289-303.

[15] Cheng J, Zou S, Chen S. Application Research on the Closed-loop Heat-source-Tower Heat Pump Air Conditioning System in Hot-summer and Cold-winter Zone [J]. Procedia Engineering, 2015, 121: 922-929.

[16] Liang C, Wen X, Zhang X. Construction and experimental research on heat pump system based on hea-t source tower [J]. CIESC Journal, 2010, 61(s2): 142-146.

[17] Wu J, Zhang G, Zhang Q, et al. Experimental investigation of the performance of a reversibly used cooling tower heating system using heat pump in winter $[\mathrm{C}] /$ /Power and Energy Engineering Conference (APPEEC), 2011 Asia-Pacific. IEEE, 2011: 1-4.

[18] Zhang X, Wen X, Liang C. New type of dual high-efficiency heat pump system suited to hot summer and cold winter zones [J]. Refrigeration and air conditioning, 2013, 13(11): 6-10.

[19] Li N, Zhang W, Wang L, et al. Experimental study on energy efficiency of heat-source tower heat pump units in winter condition $[\mathrm{C}] / / 2011$ Third International Conference on Measuring Technology and Mechatronics Automation (ICMTMA). IEEE, 2011: 135-138.

[20] Huang S, Lv Z, Zhang X, et al. Experimental investigation on heat and mass transfer in heating tower solution regeneration using packing tower [J]. Energy and Buildings, 2018, 164: 77-86.

[21] Wen X, Cao Q, Yu P, et al. Energy-saving analysis and experimental study of a new heat-source tower solution regeneration system [J]. CIESC Journal, 2018, 69(5): 2226-2232.

[22] Ahri. AHRI Standard 540, Performance rating of positive displacement refrigerant compressors and compressor units [S].Air-Conditioning, Heating, and Refrigeration Institute, 2015.

[23] Zhen X. Principles and equipment of refrigeration [M]. China Machine Press, 2001.

[24] Wu Y. Design guide of small refrigerator [M]. Machinery Industry Press, 1998.

[25] Zong L. Analysis and calculation of frosting and fefrosting loss of small air-source heat pump [J]. Journal of Qingdao Institute of Architecture and Engineering, 1999, 20(2): 61-65.

[26] Hardy B. ITS-90 formulations for vapor pressure, frostpoint temperature, dewpoint temperature, and enhancement factors in the range -100 to $+100 \mathrm{C}[\mathrm{C}] /$ Proceedings of the third international symposium on humidity and moisture,Teddington, London, England. 1998: 1-8.

[27] Eames I W, Milazzo A, Maidment G G. Modelling thermostatic expansion valves [J]. International Journal of Refrigeration, 2014, 38: 189-197.

[28] Huang S, Lv Z, Liang C, et al. Experimental study of heat and mass transfer characteristics in a cross-flow heating tower [J]. International Journal of Refrigeration, 2017, 77: 116-127.

[29] Huang S, Zuo W, Sohn M D. Amelioration of the cooling load based chiller sequencing control [J]. Applied Energy, 2016, 168: 204-215.

[30] Wang X, Zhou M, Cheng H. Calculation of moist air thermal properties [C]//The eighteenth academic conference of building heat energy branch of China Architecture Society. 2013:

[31] Ashrae. 2005 ASHRAE handbook : fundamentals [M]. ASHRAE, 2005. 
[32] Fujita T, Kikuchi S. Vapor Pressure of Aqueous Solutions of Ethylene Glycol [J]. Transactions of the Japan 2

[33] Liu X H, Geng K C, Lin B R, et al. Combined cogeneration and liquid-desiccant system applied in a

[34] Mohurd. GB 50736-2012, Design code for heating ventilation and air conditioning of civil buildings [S].China 